\title{
AVALIAÇÃO DA POSIÇÃO CONDILAR EM PACIENTES DESDENTADOS TOTAIS PORTADORES DE DENTADURAS DUPLAS, ATRAVÉS DE PLANIGRAFIAS DA ATM
}

\section{VINÍCIUS CARVALHO PORTO}

\author{
Dissertação apresentada à Faculdade \\ de Odontologia de Bauru, da \\ Universidade de São Paulo, como \\ parte dos requisitos para a obtenção \\ do título de Mestre em Odontologia, \\ área de Reabilitação Oral.
}

Orientador: Prof. Dr. Milton Carlos Gonçalves Salvador

\section{BAURU}




\title{
AVALIAÇÃO DA POSIÇÃO CONDILAR EM PACIENTES DESDENTADOS TOTAIS PORTADORES DE DENTADURAS DUPLAS, ATRAVÉS DE PLANIGRAFIAS DA ATM
}

\section{VINÍCIUS CARVALHO PORTO}

\author{
Dissertação apresentada à Faculdade \\ de Odontologia de Bauru, da \\ Universidade de São Paulo, como \\ parte dos requisitos para a obtenção \\ do título de Mestre em Odontologia, \\ área de Reabilitação Oral.
}

(Edição Revisada)

\section{BAURU}




\begin{tabular}{|l|}
\hline PORTO, Vinícius Carvalho \\
P838a $\quad$ Avaliação da posição condilar em desdentados totais portadores \\
de dentaduras duplas, através de planigrafias da ATM / \\
Vinícius Carvalho Porto. - Bauru, 2000. \\
Xi, 90p.: il.; $28 \mathrm{~cm}$. \\
Dissertação (Mestrado) - Faculdade de Odontologia de \\
Bauru. \\
Universidade de São Paulo. \\
Orientador: Dr. Mílton Carlos Gonçalves Salvador \\
\hline
\end{tabular}

Autorizo, exclusivamente para fins acadêmicos e científicos, a reprodução total ou parcial desta dissertação, por processos fotocopiadores e/ou meios eletrônicos.

Assinatura do autor:

Data: 
22 de Março de 1972

Salvador - BA

$1990-1994$

$1995-1996$

$1996-1997$

$1998-2000$

Associações
Nascimento

Curso de Odontologia, Faculdade de Odontologia da Universidade Federal da Bahia.

Professor Substituto do Departamento de Odontologia Restauradora da Faculdade de Odontologia da Universidade federal da Bahia.

Especialização em Prótese Dentária, pela Faculdade de Odontologia de Bauru, USP.

Curso de Pós-Graduação em Reabilitação Oral - Prótese, ao nível de Mestrado, na Faculdade de Odontologia de Bauru, USP.

ABO - Associação Brasileira de Odontologia - Secção Bahia.

APG - Associação dos PósGraduandos da Faculdade de Odontologia de Bauru. 
Aos meus pais, João e Lídia, pelo incentivo, apoio e compreensão nesta etapa de minha vida. Por valorizarem a educação dos filhos e por terem me proporcionado a realização de um sonho.

A minha irmã, Viviane, companheira e exemplo de como a dedicação e a responsabilidade contribuem na formação de um indivíduo.

A minha madrinha, Marlinda, que com as palavras e atitudes transmitem a tranqüilidade nos momentos mais tensos. Pela simplicidade de tornar o que a cerca em paz.

A Deus, que em todos os momentos da vida sempre se faz presente.

“E a quem a luz penetrar lá chegará."

ROLF 
A Vanessa, pela companhia, compreensão, alegria, carinho e sabedoria. Por ter se constituído na outra metade dos meus pensamentos. Por ser bela e única. Pelo ter e ser o mais puro sentimento. 
Ao Prof. Dr. Milton Carlos Gonçalves Salvador, pela atenção, gratidão e colaboração em todos os passos do meu trabalho. Mais do que um orientador, um amigo. Pela confiança que depositou em mim,

Meu profundo respeito e minha amizade. 
Aos Professores do Departamento de Prótese da Faculdade de Odontologia de Bauru- USP, pelos conhecimentos transmitidos, atenção, respeito e exemplo.

Ao Prof. Dr. Paulo César Rodrigues Conti, pela contribuição na idealização desta pesquisa.

Ao Prof. Dr. José Henrique Rubo, pela disponibilidade e atenção quando solicitado.

Ao Professor Antônio Barcelar de Rezende, pelo incentivo e brilhantismo com que conduz a Prótese.

Aos pacientes, pela confiança e amizade conquistadas.

À Faculdade de Odontologia de Bauru e à Comissão de Pós-Graduação, por tornar acessível todas as atividades desenvolvidas durante o curso.

À CNPq, pelo respaldo fornecido por meio das Bolsas de estudo no período de execução deste trabalho.

Aos Profs. Drs. Luiz Fernando Pegoraro e Gerson Bonfante, pela prestatividade e orientação profissional e pessoal, sendo exemplos a serem seguidos. 
Aos colegas de Doutorado, Luciano, Henrique, Daniel, Luís, Materson, João, Sérgio e Hideki, pela integração e amizades cultivadas durante o curso.

Aos funcionários do Departamento de Prótese, Edna, Ângela, Débora Lílian, Reivanildo, Marcelo, Luzia, Didi, Geraldo, pela atenção e prestação de serviços em todos os instantes de necessidade.

Aos funcionários da Disciplina de Radiologia José Messias, Célio e Valderez, pela importante cooperação na fase experimental desta pesquisa.

Aos funcionários da Pós-graduação e Biblioteca, por estarem sempre solícitos aos pedidos e pelo profissionalismo com que desempenham suas funções.

Ao Prof. José Roberto Lauris, pela aplicação desferida na análise dos dados estatísticos.

A todos aqueles que de alguma forma contribuíram para o sucesso deste trabalho,

Meus sinceros agradecimentos. 
Aos colegas de turma Andréia, Anuar, Carlinhos, Daniela, Juliano, Letícia, Mário, Nelsinho, Sérgio, Vágner, Vinícius Janson e William, pelo respeito, convivência e amizade.

A Luciano e Paulo Rocha, pelo fortalecimento da amizade e pelo respeito mútuo.

A Henrique e Letícia, pela compreensão e atenção desprendidas, desde a seleção para o curso.

A Paloma Dias Telles, pela luta, conquista de um objetivo e vitória alcançada.

A este trabalho agradeço, a presença de cada um de vocês que somaram para que pudesse concretizá-lo. 


\section{RESUMO}

A posição condilar tem sido questionada como importante fator na detecção de sinais e sintomas de DTM's. Por muito tempo, determinou-se que a concentricidade condilar refletiria uma posição ótima para o paciente. No entanto, outros trabalhos mostraram que era possível a visualização da descentralização dos côndilos, mesmo em pacientes assintomáticos. Dessa forma, avaliou-se neste trabalho a posição condilar antes e após instalação de PT's novas, por meio de planigrafias laterais da ATM. O critério de seleção dos pacientes foi aleatório e, mediante a amostra escolhida, foi preenchido um questionário clínico-anamnésico, seguido de tomadas radiográficas com o par de dentaduras antigas e novas em 12 pacientes. Um único examinador conduziu o preenchimento das fichas e análise das radiografias no programa de imagens Corel Draw 8. De acordo com a metodologia aplicada e análise estatística dos resultados, verificou-se que a posição condilar em desdentados totais na primeira tomada radiográfica situou-se mais para anterior em $100 \%$ dos casos. Já o deslocamento condilar após instalação das novas próteses resultou em uma tendência de deslocamento para posterior em $75 \%$ dos indivíduos, para anterior em 16,7\% e em 8,3\% não houve variação da posição condilar. Dos 18 côndilos (75\% casos) com deslocamento para posterior, apenas 1 côndilo assumiu uma posição levemente posterior, tendo os demais se localizado concentricamente ou para anterior. Não houve qualquer correlação estatisticamente significativa entre variações das posições condilares e dimensões verticais de oclusão. Provavelmente, os deslocamentos condilares encontrados sejam justificados pelas manipulações com forças variadas, aplicada pelos profissionais, para a posição de trabalho 
(RC). Baseado na literatura, a tendência de localização para posterior possivelmente não irá causar danos aos pacientes, tendo em vista se tratarem de indivíduos assintomáticos. 


\section{LISTA DE ABREVIATURAS}

1. ATM - Articulação Temporomandibular

2. DTM's - Desordens Temporomandibulares

3. DVO - Dimensão Vertical de Oclusão

4. JIG - "Joint Interference Guide"

5. MBM - Manipulação Bilateral Mandibular

6. MIH - Máxima Intercuspidação Habitual

7. MGP - Método Guiado com o Polegar no Queixo

8. PSC - Ponto Superior Condilar

9. PT's - Próteses Totais

10. RC - Relação Cêntrica

11. RM - Ressonância Magnética

12. TC - Tomografia Computadorizada

13. TR's - Radiografias Transcranianas 


\section{SUMÁRIO}

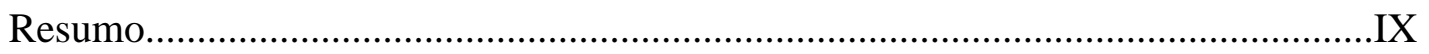

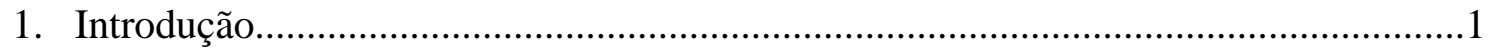

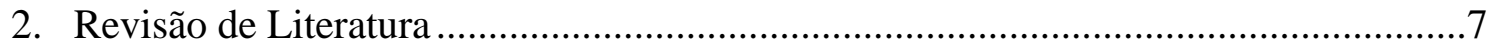

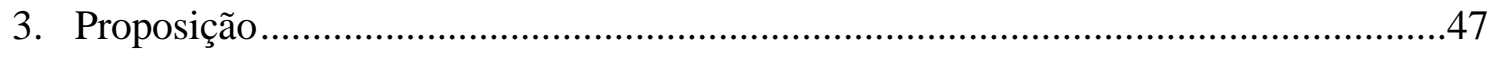

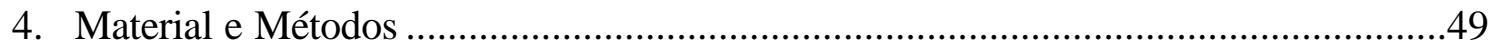

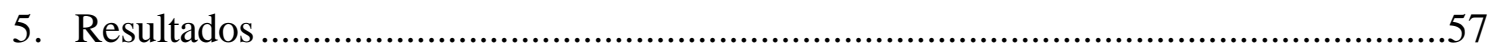

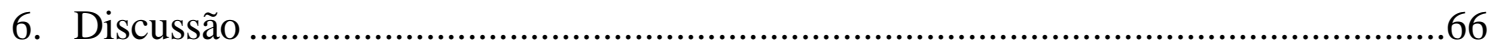

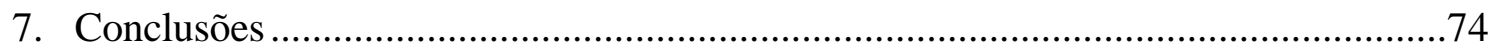

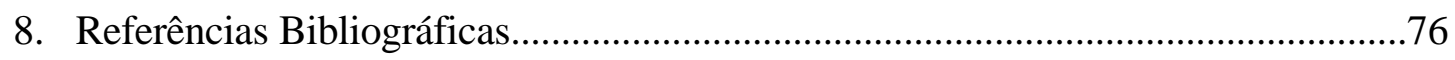

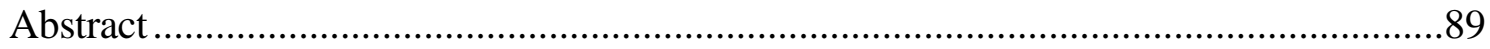


1- INTRODUÇÃO 


\section{1- INTRODUÇÃO}

A articulação temporomandibular (ATM) é uma articulação sinovial, bilateral, composta basicamente da fossa articular, fibrocartilagem, fibras nervosas, côndilo e disco articular, que atuam em conjunto em todos os movimentos mandibulares.

Dentro deste contexto, os côndilos, que são componentes importantes da ATM, apresentam-se em duas unidades, localizando-se na extremidade do osso mandibular.

Formados por osso denso mineralizado, os côndilos possuem formas e extensões diversas, visto sua peculiar capacidade de remodelação e por conseguinte modificação da forma. Freqüentemente essas mudanças estão relacionadas a perdas ou abrasões dentárias. Essa remodelação pode ser considerada, até certo ponto, como uma adaptação funcional da nova relação interoclusal, já que, quando cargas incidentes excedem o limite de tolerância fisiológica, há uma perda de equilíbrio deixando de ser funcional para ser patológica. ${ }^{34}$

Com o aumento da idade, a superfície superior do côndilo tende a ficar aplainada, acompanhada por aumento progressivo da profundidade da fossa articular. ${ }^{65}$ No transcorrer de atividades funcionais, os côndilos desempenham movimentos de rotação e translação, sendo facilmente observados quando projetados num plano sagital.

Assim, as estruturas condilares têm sido alvo de vários estudos na literatura como, por exemplo, a sua relação com a fossa glenóide, 
freqüentemente abordada na presença dos dentes naturais e, em alguns casos, na ausência total destes.

Para tanto, uma imensa quantidade de técnicas de imagem são disponíveis para exame da ATM, incluindo a tomografia linear ou laminografia, radiografia transcraniana (TR), radiografia panorâmica, artrografia, tomografia computadorizada (TC) e ressonância magnética (RM).

A radiografia panorâmica, embora ofereça excelentes dados sobre anormalidades condilares, não permite informações valiosas sobre $o$ relacionamento côndilo/fossa, devido à grande superposição de tecidos ósseos.

Por meio da artrografia, é possível obter-se uma percepção precisa do disco articular, sendo uma das técnicas utilizadas no auxílio diagnóstico dos desarranjos internos da ATM, apesar de sua característica invasiva.

A TC tem indicação na investigação de pacientes com desarranjos internos da ATM, enquanto a RM consiste de uma técnica rápida, livre de radiações, não invasiva e com grande capacidade de visualização minuciosa dos tecidos moles. Ambas, contudo, possuem custos elevados, o que faz muitos clínicos preterí-las por técnicas radiográficas mais simples.

A TR permite a visualização da porção lateral do côndilo. $O$ ângulo formado entre o filme e o tubo de raios-x varia de 16 a 30 graus. $\mathrm{O}$ feixe de raios-x atravessa acima de ambos os côndilos e a base do crânio. 
Esta técnica de avaliação possui baixa dose de radiação e custo relativamente inferior às tomografias ${ }^{54}$.

A tomografia é uma técnica que minimiza a superposição de imagens. Uma fina secção predeterminada pode ser selecionada para radiografar, sendo que todas as estruturas circunvizinhas ficam nebulosas e turvas na imagem. $\mathrm{O}$ tubo de raios- $\mathrm{x}$ e o filme são sincronizados para se movimentarem em direções opostas sobre um eixo de rotação fixo ${ }^{24}$.

Variações na projeção do suporte dos raios-X, bem como a posição da cabeça, podem produzir mudanças na articulação, simulando deslocamentos condilares. Assim, determina-se que a posição do côndilo não pode ser comparada em radiografias seriadas, ao menos que se tenham feito projeções idênticas ${ }^{26}$. WEINBERG ${ }^{58,62}$ mostrou que pequenas variações podem ser vistas quando radiografias foram comparadas em idênticas projeções realizadas em tempos de tomadas diferentes. KUNDERT ${ }^{26}$ afirmou que diferenças de $0,2 \mathrm{~mm}$ são percebidas sob condições clínicas.

A concentricidade do côndilo na fossa foi proposta como uma relação ótima ao nível radiográfico, com muitos autores associando a não concentricidade com desordens temporomandibulares (DTM's) tais como desarranjos internos, remodelação óssea desequilibrada, deslocamento condilar posterior e degenerações articulares $34,35,58,59,60$.

A possível visualização de deslocamentos condilares para posterior em técnicas radiográficas convencionais, associados com dor e estalido articular, pode sugerir a necessidade de exames mais precisos para confirmação diagnóstica de uma DTM ${ }^{46,47}$. 
WEINBERG $^{58}$, utilizando TR's em pacientes com DTM, observou que a perfeita oclusão deve ser estabelecida quando os côndilos estivessem simetricamente posicionados na fossa, com iguais espaços articulares anterior e posterior. No entanto, outros estudos mostram uma alta porcentagem de não concentricidade compatível com normalidade em indivíduos assintomáticos ${ }^{43}$.

As possíveis causas dos deslocamentos condilares são atribuídas à própria formação anatômica, à mastigação unilateral, aos períodos de repouso, ao deslocamento do disco articular e ao edentulismo.

A perda total dos dentes é uma dolorosa realidade, seja por fatores relacionados à cárie dentária ou às doenças periodontais. Dentro desse enfoque, as próteses totais (PT's) podem ser consideradas alternativas reabilitadoras ao paciente mutilado. O sucesso do tratamento das PT's exige um sistemático e completo exame, a fim de avaliar o estado físico e psicológico do paciente desdentado, as condições orais, as histórias médica e odontológica pregressas e raios-X.

Dentro dos procedimentos técnicos de execução de PT's, a obtenção de registros intermaxilares precisos, tais como a relação cêntrica (RC) e dimensão vertical de oclusão (DVO), constituem ainda um grande desafio ao profissional.

No paciente desdentado que venha a substituir as próteses antigas geralmente há necessidade que se restabeleçam essas medidas corretamente. Para tanto, vários são os métodos existentes, visando devolver as funções 
normais de um indivíduo. Ao se restabelecer as dimensões perdidas pelo paciente, provavelmente haverá uma mudança de posição condilar, tendo em vista que a movimentação da mandíbula -um osso móvel- também implica em movimentação do côndilo.

Sob esse aspecto, as dúvidas observadas na variação da posição do côndilo, após a substituição das PT's, nos levam a estudar as possíveis variações desse posicionamento na DVO e RC dos pacientes, quando com as dentaduras em uso e posteriormente a instalação das novas PT's, por meio de planigrafias laterais da ATM. 
2- REVISÃO DA LITERATURA 


\section{2- REVISÃO DA LITERATURA}

MARTIN ${ }^{31}$, em 1951, investigou a posição do côndilo e interpretou de forma rudimentar através de radiografias. Centenas de crânios, obtidos do Museu de Chicago, compuseram a amostra, sendo que apenas trinta apresentavam uma oclusão ideal. Impressões em cera foram feitas de cada ATM, com os crânios devidamente ocluídos em máxima intercuspidação habitual (MIH). Posteriormente, registros radiográficos foram executados de cada lado, orientados pelo plano horizontal de Frankfort e utilizando aparelho idealizado por LINDBLOM ${ }^{25}$. Cada impressão foi vazada em gesso pedra e recortada bem próxima ao limite das articulações, para que se pudesse fazer as comparações com as radiografias. As radiografias ofereceram uma descrição precisa da relação que existe na ATM.

HEDEGARD; LUNDBERG ${ }^{17}$, em 1965, pesquisaram se de fato existia qualquer modificação da fossa mandibular e tubérculo articular num pequeno grupo de 15 pacientes, com acompanhamento de 10 anos, após instalação de próteses imediatas superiores, por meio de radiografias. Os critérios para seleção dos pacientes basearam-se nas condições gerais de saúde, presença de dentes remanescentes na maxila e mandíbula, ausência de problemas periodontais severos e necessidade de prótese imediata apenas no arco superior. As medidas foram padronizadas na mesma posição através de um cefalostato. Os resultados indicaram que não ocorreram variações significativas na fossa mandibular e tubérculo articular nos 10 primeiros anos. 
LOISELLE $^{30}$, em 1969, avaliou a relação de fatores oclusais com DTM's em 2000 pacientes de um hospital. A mera presença de estalidos sem limitação da função ou hipermobilidade não foi considerada suficiente para se caracterizar na categoria de desordens. $6 \%$ dos pacientes com dentição natural completa, $16 \%$ com dentes mutilados e $26 \%$ com próteses totais não foram classificados como desordens da ATM. Estresse emocional e outros fatores etiológicos têm sido observados como desencadeadores de problemas disfuncionais e para isso terapias com placas lisas com liberdade em movimentos excêntricos têm sido propostas pelo autor.

SMITH; HARRIS ${ }^{54}$, em 1970, revisaram técnicas padrões para radiografias da ATM com considerações clínicas das suas indicações. Segundo os autores, as TR's confirmam o diagnóstico de restrição do movimento condilar do lado afetado, onde houver presença de espasmo e dor muscular. As tomografias e radiografias panorâmicas mostram as deformidades do côndilo assim como as radiografias póstero-anterior (PA) e as submento-verticais, sendo que as duas últimas também visualizaram hiperplasias condilares. A técnica de Towne's modificada, a transorbital e a transfaríngea são capazes de visualizar fraturas condilares. Ressaltaram que as radiografias, por melhor que sejam, são instrumentos utilizados com a finalidade de confirmação de diagnóstico clínico.

KLEIN; BLATTERFEIN; MIGLINO ${ }^{24}$, em 1970, dissecaram 200 cadáveres e estudaram radiograficamente 100 destes com o objetivo de examinar e ter conhecimento das estruturas da ATM. A área dissecada foi anterior ao meato acústico externo. Contrário ao que se esperava, foi mais difícil radiografar um cadáver do que um ser vivo, por causa da posição que o côndilo assume pós-morte, bem como da dificuldade de posicionar a 
cabeça e odor desagradável. Tomografias foram escolhidas para se minimizar a superposição das estruturas. Portanto, foi possível determinar a fidelidade das TR's e tomografias em relação às estruturas articulares e que as variações não podem ser observadas em um único plano radiográfico. As tomografias realizadas em vários planos oferecem uma útil descrição das estruturas da ATM, além de prover meios para observar a simetria e assimetria dos movimentos condilares.

WEINBERG ${ }^{62}$, em 1973 e reiterado em $1985{ }^{58}$, descreveu a relação funcional da ATM e seu efeito sobre a RC. Quando a RC fosse igual a MIH, a RC era classificada como funcional desde que os espaços articulares estivessem simétricos e os côndilos posicionados concentricamente na porção superior da fossa glenoíde. Se um dos côndilos estivesse retruído, a RC era considerada disfuncional. Se existisse um deslize, a RC poderia ser classificada como funcional, se o deslocamento condilar nas radiografias da ATM se correlacionasse com a direção e magnitude da deflexão mandibular. Quando a posição condilar não se correlacionava com a deflexão mandibular, a RC era classificada como disfuncional. Neste caso, foi necessária a intervenção por meio de ajustes oclusais e próteses fixas, conseguindo resultados aceitáveis mediante visualização radiográfica.

WILKIE; HURST; MITCHELL ${ }^{63}$, em 1974, compararam radiograficamente a relação côndilo/fossa durante registros maxilomandibulares na $\mathrm{MIH}, \mathrm{RC}$ e estimulação muscular através de um eletrodo de superfície, sendo que para os dois últimos utilizava-se desprogramador oclusal anterior em resina autopolimerizável - Joint Interference Guide - (JIG). A avaliação foi realizada em 10 homens com 
todos os dentes naturais e média de idade de 35 anos. A posição do côndilo foi caracterizada como: (1) centrada, quando existia iguais distâncias do côndilo em relação à fossa tanto para anterior quanto para posterior; (2) anterior, quando existisse menor distância do côndilo em relação à parede posterior da eminência; (3) posterior, quando houvesse menor distância posterior. A fossa glenóide serviu como referência reproduzível na análise comparativa das radiografias. Um total de $70 \%$ dos côndilos estavam centrados na fossa glenóide. Na RC e MIH, os côndilos mostraram-se centrados em 8 indivíduos, sendo um na posição posterior e um na anterior. Através do método da estimulação muscular, em 5 indivíduos, os côndilos estavam mais para anterior e os outros 5 apresentaram-se centralizados.

SHAFAGH; YADER; THAYER ${ }^{53}$, em 1975, investigaram as variações diurnas da posição de RC. Foram selecionados 10 homens e 3 mulheres com oclusão classe I de Angle, com média de idade de 20 a 30 anos, advindos da Universidade de Iowa. Todos possuíam dentição natural completa com mínimas restaurações e sem evidências de disfunções fisiológicas ou sistêmicas. Três horas específicas do dia foram usadas para estudo: 9:00 A.M, 3:00 P.M e 9:00 P.M. Seis registros interoclusais em RC foram feitos, nas determinadas horas, para cada paciente. Por causa da variação da mobilidade dos dentes num dia, todas as impressões foram realizadas pela tarde antes do dia dos testes. A manipulação manual guiada e emprego de um JIG auxiliaram no estudo, sendo a posição de RC registrada com pasta de óxido de zinco e eugenol. Para comparação, utilizou-se pontos de referência sobre os modelos marcados em cores diferentes. Os resultados mostraram uma grande variabilidade da posição de RC na maioria dos indivíduos analisados, nas diferentes horas estudadas. Isto deve-se às várias formas anatômicas e conteúdo do fluido das ATM's. 
CARLSSON ${ }^{5}$, em 1976, revisou sintomas correlacionados a disfunção em pacientes portadores de PT's, constatando alta incidência de osteoartrose e dores musculares e que o melhoramento da oclusão, na maioria dos casos, funcionou como uma medida terapêutica importante na resolução das desordens apresentadas pelos indivíduos edêntulos.

WILLIAMSON ${ }^{66}$, em 1978, determinou radiograficamente em 20 pacientes assintomáticos a diferença da posição condilar quando a mandíbula era posicionada mais posteriormente, comparando com um método fisiológico por meio de um guia anterior e considerando espaço articular normal quando o mesmo dispositivo anterior for usado. A primeira tomada radiográfica foi feita com a mandíbula na posição mais posterior, sendo o paciente instruído a fechar vagarosamente até o primeiro contato (instante da exposição). Uma segunda tomada foi registrada nessa posição aproveitando o suporte para a cabeça. Com a confecção do guia anterior, o paciente foi instruído a fechar com força moderada e a segunda exposição foi executada. As radiografias obtidas foram traçadas com lápis mais fino (primeira tomada) e lápis mais grosso (segunda tomada) para que se pudesse fazer uma diferenciação dos métodos utilizados. Foi necessário sobrepor as radiografias em estruturas anatômicas constantes e estáticas para que se validasse a avaliação. Nesta avaliação, foram usados instrumentais como a régua milimetrada e um compasso, levando-se em consideração as seguintes análises da posição condilar: anterior, a menor distância entre a superfície anterior do côndilo e o declive posterior da eminência; posterior, a menor distância entre a superfície posterior do côndilo e a superfície posterior da fossa glenóide; superior, a menor distância entre a superfície superior do côndilo e o ápice da fossa glenoíde. Uma larga variação das posições condilares foi verificada. A média de movimento do côndilo para superior 
com guia anterior foi de aproximadamente $0,9 \mathrm{~mm}$, com uma variação de 0,5 a 2,5mm. A média para inferior foi de $1,0 \mathrm{~mm}$. A média para anterior foi de 0,98mm, com uma variação de 0,5 a 2,0 $\mathrm{mm}$. Para posterior, a média foi de 0,9mm, com uma extensão de 0,5 a 1,0mm. Em relação ao espaço articular, as médias foram de 2,2mm (variação de 1,0 a 4,0mm) para anterior; 2,0mm (variação de 1,0 a 3,0mm) para posterior; e 3,4mm (variação de 1,0 a $5,0 \mathrm{~mm}$ ) para superior. Concluíram que os dados mais significantes foram observados na relação mais superior do côndilo na fossa glenóide, quando se utilizou um guia anterior.

KUNDERT ${ }^{26}$, em 1979, investigou o valor limite de deslocamento do côndilo detectável por meio de diferentes radiografias com projeções idênticas, e os fatores capazes de influenciar este deslocamento. Um total de 11 estudantes da escola de Odontologia de Zurique, sem sinais e sintomas de disfunção e presença de todos os dentes naturais (exceção aos terceiros molares) foi selecionado. Confeccionou-se uma placa individual no maxilar para o traçado do arco gótico descrito de acordo com os movimentos mandibulares. A cabeça do paciente foi fixada através de uma banda de borracha para evitar variações de posição. A primeira exposição foi denominada de posição 0 , sendo as exposições subseqüentes efetuadas mediante avanços de $0,2 \mathrm{~mm}$ da mandíbula para frente. Para avaliação dos resultados, um total de 12 dentistas foi dividido em três grupos de acordo com sua experiência quanto à análise radiográfica da ATM. No primeiro grupo, os profissionais apresentavam valiosa experiência. $\mathrm{O}$ segundo e terceiro grupos representavam clínicos com boa experiência ou nenhuma com radiografias da ATM, respectivamente. O valor médio de limite de percepção foi de $0,61 \mathrm{~mm}$. O menor valor foi de $0,2 \mathrm{~mm}$ e o maior de $1,2 \mathrm{~mm}$. Alguns fatores influenciaram o limiar dos valores, dentre eles a qualidade 
técnica das radiografias. A partir daquelas com melhor qualidade, as variações das posições condilares eram menores, enquanto naquelas com pior distinção as variações foram maiores. A interpretação variável das radiografias, com uma melhor percepção no primeiro e segundo grupos, e a interpretação do espaço articular posterior diferenciando da posição que o côndilo ocupa, também influenciaram a análise dos resultados, neste trabalho.

MIKHAIL; ROSEN ${ }^{33}$, em 1979, determinaram a correlação entre sinais e sintomas de DTM e a localização do côndilo na fossa, por meio de mensuração do espaço articular, em radiografias realizadas com um posicionador para a cabeça. Três grupos de pacientes compuseram a amostra: (1) pacientes com disfunção, (2) amostra aleatória e (3) pacientes que se submeteram a reabilitações oclusais. Este último grupo foi subdividido em (a) pacientes que tinham sinais/sintomas antes da terapia e que tiveram melhora após o tratamento, (b) pacientes sem sinais antes e após tratamento, (c) pacientes que continuaram com os sinais após tratamento e (d) pacientes sem sinais antes da terapia e que apresentaram sintomatologia após tratamento. Um completo exame clínico foi obtido dos pacientes, além de radiografias da ATM, estando os dentes em MIH auxiliado por um suporte para a cabeça. Os resultados mostraram que, no grupo dos pacientes com disfunção, $88 \%$ tinham assimetria do espaço articular, 58,7\% retrusão condilar e 23,7\% protrusão condilar. No grupo da amostra aleatória, 25\% tinham sinais/sintomas de disfunção, $89,5 \%$ assimetria dos espaços articulares, $34,1 \%$ retrusão condilar e $36,7 \%$ protrusão. No terceiro grupo, naqueles que melhoraram após tratamento, $81,3 \%$ apresentaram-se com simetria bilateral dos espaços articulares e 18,7\% com bilateral assimetria, o que sugeriu para os côndilos uma localização mais concêntrica na fossa. Do 
subgrupo sem sinais antes e após terapia, 62,5\% tinham simetria bilateral, $18,75 \%$ protrusão bilateral condilar e 18,75\% retrusão bilateral condilar. Do subgrupo sem melhoras após tratamento, 91\% tinham espaços articulares assimétricos, 72,6\% retrusão condilar. Somente um paciente que desenvolveu sinais após tratamento tinha retrusão bilateral do côndilo. O uso de suporte para cabeça ofereceu um valioso dispositivo no diagnóstico e plano de tratamento de pacientes com DTM.

WEINBERG ${ }^{60}$, em 1979, avaliou o papel da posição condilar nas disfunções da ATM em 116 pacientes, dos quais 55 faziam parte do grupo com desordem e 61 do grupo controle. Daqueles que apresentavam desordem, $71 \%$ tinham retrusão condilar ( $40 \%$ unilateral e $31 \%$ bilateral), $18,2 \%$ para anterior, $7,3 \%$ superior e $3,6 \%$ centrados. No grupo controle, $36 \%$ estavam retruídos ( $21 \%$ unilateral e $14,7 \%$ bilateral), $10 \%$ estavam para superior, $23 \%$ centrados e $31 \%$ para anterior. Observou-se que a retrusão condilar foi vista com bastante freqüência no grupo controle, indicando que quando se obtém a RC, manipulando-se a mandíbula na posição mais posterior, não necessariamente se orienta o côndilo corretamente na fossa como comumente era pensado. $\mathrm{O}$ autor ressaltou também que, quando a posição condilar dentro da fossa for significativa, a radiografia da ATM é sempre indicada.

CHOY; SMITH ${ }^{7}$, em 1980, observaram a prevalência de DTM's em 160 pacientes portadores de dentaduras da Universidade de Washington. Um questionário com 18 perguntas somado com os dados obtidos do exame clínico foram armazenados num computador. Os sons articulares foram determinados por meio de um estetoscópio, a sensibilidade articular através de palpação digital bilateral e os músculos da mastigação e outros do 
pescoço e cabeça foram inspecionados por firme palpação com os dedos. As dores musculares foram classificadas como negativa, leve, moderada ou severa, dependendo da reação do paciente. Os resultados mostraram que 15\% dos pacientes possuíam distúrbios da ATM, sendo os mais freqüentes a sensibilidade muscular, os sons articulares e a restrição dos movimentos funcionais. Salientaram que o questionário não representou um método confiável para a identificação inicial de distúrbios articulares e que exames de rotinas de pacientes com dentaduras devem incluir palpações da cabeça, pescoço e da ATM.

ISMAIL; ROKNI ${ }^{21}$, em 1980, avaliaram radiograficamente a diferença na relacão côndilo-fossa quando a mandíbula estivesse em posição de RC e MIH. Foram selecionados 40 pacientes classe I de Angle, sem interferências oclusais, com poucas ou nenhuma restauração olusal, sem sinais e sintomas de DTM e com saúde dos tecidos periodontais. Um JIG foi confeccionado para cada indivíduo e a mandíbula foi guiada enquanto se obtinham as radiografias. Foram feitas 4 exposições de cada paciente (duas em cêntrica e duas em habitual). Linhas tangentes paralelas foram desenhadas diretamente sobre as radiografias e uma distância entre elas foi medida o mais próximo de $0,1 \mathrm{~mm}$. Para o espaço superior, uma linha "a" foi desenhada tangente ao ponto mais superior da fossa e uma linha " $b$ " foi desenhada tangente ao ponto mais superior do côndilo e paralelo à linha "a". Para assegurar a confiabilidade dos resultados, utilizou-se de análises intra e interexaminadores. A média dos valores das medidas do espaço articular esquerdo, com a mandíbula em RC, foi de 2,81 mm superiormente; $2,40 \mathrm{~mm}$ anteriormente e 1,92mm posteriormente. Em $\mathrm{MIH}$, a média de valores foi de 3,$05 ; 2,10$ e 2,28mm respectivamente. A média de valores para o espaço articular direito em $\mathrm{RC}$ foi 2,$70 ; 2,30$ e $1,94 \mathrm{~mm}$ respectivamente e em 
habitual, 2,82; 2,11 e 2,14mm respectivamente. Estes resultados indicaram que os côndilos foram posicionados para posterior e superior na posição de $\mathrm{RC}$.

MONGINI ${ }^{34}$, em 1980, observou a influência da terapia oclusal no processo de remodelação e na forma condilar. Foram selecionados 7 homens e 15 mulheres com DTM. Tomografias foram desenvolvidas em planos distintos na MIH, e TR's também foram realizadas em 16 pacientes na MIH para avaliação adicional da posição condilar. O tratamento oclusal incluiu 21 pacientes com placas oclusais, 7 com desgaste seletivo, $10 \mathrm{com}$ reabilitação protética e 2 com tratamento ortodôntico. Tomografias pré e pós-tratamento foram feitas para verificar se qualquer variação da forma tinha ocorrido, considerando como variações se visíveis em pelo menos dois planos de cada lado. Achatamento condilar foi observado em pelo menos dois planos das tomografias em 11 pacientes (5 bilaterais e 6 unilaterais), sendo que no restante os côndilos mostraram-se arredondados. Após tratamento, 7 dos 11 pacientes que se mostraram com achatamento tenderam a uma nova forma mais arredondada e nenhuma variação foi percebida nos côndilos que foram previamente classificados como arredondados após as terapias.

CARWELL; McFALL ${ }^{6}$, em 1981, compararam determinações da RC clinicamente e radiograficamente. As TR's foram padronizadas com ângulo de 30 graus em relação ao suporte. Foram realizadas tomadas de cada articulação utilizando os métodos guiados do polegar no queixo (MGP) e manipulação bilateral mandibular (MBM) em 10 pacientes. A posição condilar foi determinada por traçados e mensurações diretas nas radiografias por intermédio de dois observadores treinados, empregando o método duplo- 
cego. Os traçados feitos a partir da manipulação MGP estavam desenhados em vermelho e o MBM em azul. A média dos valores das medidas radiográficas não apresentou diferenças significativas no espaço articular anterior, superior e posterior, entre as técnicas MBM e MGP. Houve uma tendência, na técnica MGP, de posicionar os côndilos mais superior e posteriormente, mas não significativa estatisticamente. Segundo os autores, vários fatores afetaram os resultados radiográficos, dentre eles a variação da posição condilar, que foi pequena, tornando difícil a precisão das mensurações. $\mathrm{O}$ uso de cera para registro pode ter introduzido erros ao exame e, portanto, um material mais firme poderia ter conseguido melhor precisão. $\mathrm{O}$ paciente também poderia não estar totalmente relaxado na tomada radiográfica como estava ao exame clínico.

MOGINI ${ }^{35}$, em 1981 , avaliou 8 homens e 22 mulheres de 18 a 60 anos através de TR's com o paciente estando em MIH, utilizando uma angulação de 22 graus em relação ao plano horizontal e 10 graus em relação ao plano frontal. Tomografias laterais também foram desenvolvidas em 5 a 7 planos, avaliando a posição, forma e alterações condilares. Comparando os resultados obtidos pelos dois métodos foi mostrado que a forma dos côndilos nas TR's foi similar aos planos medial e lateral das tomografias. Em relação à posição e às alterações condilares, estas se mostraram mais evidentes nas tomografias do que na TR. Este trabalho confirmou a importância da radiografia no tratamento, salientando que as TR's têm valor considerável na posição condilar, mesmo que a imagem só reproduza o aspecto sagital.

PRETI et al. ${ }^{41}$, em 1982, objetivaram esclarecer a relação entre a cabeça do côndilo e a fossa mandibular em MIH, em 40 crânios secos que possuíam todos os dentes, ausência de cáries e restaurações, intercuspidação 
estável, curvas de Spee e Wilson normais e oclusão classe I de Angle. Uma moldagem da ATM com silicona de adição foi realizada. Três agulhas foram implantadas no molde na direção do longo eixo da eminência, sendo uma no meio e as duas outras $5 \mathrm{~mm}$ para lateral e $5 \mathrm{~mm}$ para medial. O molde foi vazado em gesso pedra e, após a presa, uma linha foi traçada no longo eixo das agulhas e três outras perpendiculares a esta, correspondendo à direção das agulhas. Com as três secções, foi possível julgar a relação côndilo-fossa através de laminografias ou tomografias. Os resultados revelaram que o côndilo esteve posicionado levemente para anterior, o que poderia ser justificado pelas modificações ósseas ocorridas durante o processo de dissecação.

HELLSING; ISBERG-HOLM; McWILLIAM ${ }^{18}$, em 1983, desenvolveram um exame a partir do qual visualizaram diretamente a TR das diferentes posições do côndilo quando da manipulação manual (MGP) e bimanual guiadas (MBM) com JIG interposto, estabilizando a mandíbula durante a tomada radiográfica. Com a utilização do JIG, foi possível também comparar os contatos primários obtidos nas duas técnicas. Um grupo de 15 alunos (10 homens e 5mulheres) da escola de Odontologia de Estocolmo, livres de sinais e sintomas de DTM's com no mínimo 28 dentes na dentição, foram avaliados quanto à RC pelo mesmo operador. Para verificação do primeiro contato em MGP, foi utilizado papel carbono preto e, em MBM, papel carbono vermelho. As tomadas da TR foram registradas nas duas posições com os devidos dispositivos de acrílico interpostos. Os resultados mostraram que não houve diferenças significativas entre as duas técnicas radiograficamente. Em MBM, 13 côndilos estavam para superior, 14 estavam inferiormente e 3 iguais à MGP. Paradoxalmente, 17 côndilos estavam mais para posterior em MBM do que em MGP (posição retruída), 
enquanto que 13 côndilos estavam mais para anterior, concluindo que a denominação de MGP e MBM não são relevantes. Em relação aos contatos, MBM foi mais levemente posterior do que MGP, o que reflete uma rotação distal da mandíbula durante a manipulação bimanual.

KATZBERG et al. ${ }^{23}$, em 1983, compararam por meio de artrografia, a relação côndilo-fossa em 82 pacientes com e sem desarranjos internos como dor, sensibilidade, travamento ou estalido das ATM's após insucessos com métodos conservadores. Tomografias lineares foram realizadas antes das artrografias. As posições de MIH e máxima abertura bucal foram obtidas para análise. Algumas referências foram utilizadas para a realização deste estudo, os autores inicialmente desenharam uma linha de referência horizontal a partir da fissura escamotimpânica (ponto $S$ ) até o ápice da eminência articular (ponto E).O ponto mais anterior, $\mathrm{Y}$, foi interligado ao ponto mais posterior, $\mathrm{X}$, e do meio desta linha partiu uma perpendicular dividindo a fossa condilar e espaço articular ao meio. Após a injeção de contraste, imediatamente realizaram-se as tomografias laterais. Não houve diferenças significativas entre os grupos comparados nos quais os dados estatísticos mostraram-se irrelevantes.

VAN SICKELS; BIANCO; PIFER ${ }^{57}$, em 1983, obtiveram dados comparativos entre imagens TR's e tomografias de 61 pacientes com queixas de desordens ou dores da ATM, num período de 4 meses. As posições examinadas foram a MIH, posição em repouso e abertura máxima. Os pacientes primeiramente foram examinados, com devido preenchimento da história pregressa e avaliação das TR's e, diante disto, indicada uma placa estabilizadora. Se não houvesse um resultado esperado, tomadas tomográficas e artrotomográficas seriam registradas, sendo que, do total, 
apenas 4 realizaram este estudo de forma bilateral e 7 unilateralmente. Os resultados acusaram que as TR's visualizaram variações de posição e estruturais do terço lateral do côndilo e da fossa. TR's obtidas com angulações superiores a 20 graus produziram distorções significativas na abertura máxima e as variações estruturais verificadas nas tomografias foram tão severas ou mais extensas do que as vistas nas TR's. Outra afirmação proveniente desse estudo é que as tomografias e artrotomografias são recursos utilizados no caso de inconsistência de informações obtidas a partir da terapia inicial. O motivo que talvez tenha levado à discrepância entre TR's e artrotomografias foi a angulação vertical empregada ou distensão dos tecidos moles posteriores, mimetizando normalidade na relação côndilo/fossa.

WILLIAMS ${ }^{64}$, em 1983, revisou os achados fornecidos pela técnica de tomografia linear da ATM e aplicou esta técnica para comparar articulações normais e anormais. A relação côndilo/eminência e espaço articular superior foi estudada em 20 indivíduos assintomáticos e 20 sintomáticos. Estes últimos apresentavam problemas como deslocamento do disco para anterior com estalido recíproco, estalidos simples na abertura ou fechamento e deslocamentos do côndilo com limitação dos movimentos. Uma diferença significativa foi encontrada entre dois grupos estudados, quanto à posição condilar.

HANSSON; HANSSON; PETERSSON ${ }^{15}$, em 1983, compararam achados clínicos e radiográficos em 259 pacientes com DTM. Foi realizado exame clínico que consistiu da verificação da máxima abertura bucal expressada em milímetros, assim como da observação de deslize de RC para MIH. Sons articulares foram auscultados por meio de estetoscópios, além do 
exame da sensibilidade dos músculos e da ATM à palpação. Foram notados, ao nível dentário, perda de suporte (pré-molar e molar) e desgastes dentários. As radiografias empregadas foram a projeção submentovértex, TR's e projeção transmaxilar. Tomografias foram tomadas em apenas 30 pacientes. Nas TR's, a posição do côndilo foi acessada na posição de MIH, sendo classificada como anterior, central, posterior, superior e inferior. Não foi possível identificar, em 12 radiografias, a posição condilar; contudo, nas 506 ATM's restantes, 128 estavam concêntricas, 81 anteriores, 250 posteriores, 13 superiores e 34 inferiores. A correlação entre os achados clínicos e radiográficos mostrou que uma alta prevalência de variações da estrutura óssea, com perda do molar de suporte e estalido articular, estava relacionada com a posição mais para posterior do côndilo. A confiabilidade do resultado das TR's é de difícil distinção, pois não se sabe se a posição posterior do côndilo seria uma consequiência das variações teciduais ou uma distorção dependente das projeções.

MEJERSJO; HOLLENDER ${ }^{32}$, em 1984, investigaram a relação entre achados clínicos e radiográficos, obtendo informações a respeito das variações que ocorrem nas articulações após ter sido completado o tratamento para dor/disfunção das ATM's. O trabalho envolveu 124 pacientes, avaliados num intervalo de 7 anos, sendo aqueles com diagnóstico de desordens musculares ou articulares sistêmicos excluídos. O exame radiográfico incluiu projeções submentovertical, TR's e radiografias transmaxilares, todos avaliados por dois examinadores. Pacientes com diagnóstico de osteoartroses tinham consideravelmente mais imagens radiográficas do que aqueles com dor/disfunção ou estalido articular. Foi percebido que, em pacientes com reduzido número de pontos de contatos, crepitação e redução do suporte na região de molares, havia diminuição do 
espaço articular e que estalidos articulares estavam acompanhados com posição mais posterior dos côndilos.

HANSEN; AXINN ${ }^{14}$, em 1984, avaliaram a freqüência de ocorrência das DTM's em 200 portadores de dentaduras (52 mulheres e 148 homens) em pelo menos um arco, quando as deixavam fora da boca enquanto dormiam. Foram selecionados aleatoriamente e submetidos a um questionário, baseado em critérios previamente estabelecidos que consistiam de: (a) uso da dentadura no mínimo a 1 ano; (b) não conhecimento por parte dos clínicos da presença de sintomas de disfunção; (c) e satisfação dos pacientes em relação ao uso da prótese total. Os pacientes foram avisados a responder "sim" ou "não", com o objetivo de não intimidar o questionamento, além de não se exigir a identificação pessoal. Dos selecionados, $25 \%$ indicaram sintomas semelhantes àqueles vistos em disfunções, quando dormem sem as dentaduras, experimentando mais de um sintoma. A queixa mais comum foi a sensibilidade articular. Aconselharam que pacientes portadores de dentaduras devem usá-las enquanto dormem, apesar do comprovado efeito prejudicial para os tecidos bucais que servem de suporte para as mesmas.

RIEDER; MARTINOFF ${ }^{50}$, em 1984, avaliaram através de TR's , 926 pacientes em MIH com o uso de um posicionador, visando uma maior padronização dos resultados, a posição condilar, o espaço articular e as variações morfológicas das estruturas da ATM. Apresentavam falta de concentricidade condilar 53\% dos pacientes, sendo a protrusão mais comum nos homens e a retrusão nas mulheres. A falta de concentricidade foi relacionada com o aumento das DTM's. A maioria das mulheres possuía espaço articular reduzido e o seu aumento estava relacionado com o aumento 
da idade. Outra análise a partir destes dados foi a de que o aumento dos espaços articulares estava vinculado com as disfunções articulares. $\mathrm{O}$ maior número de alterações morfológicas se observou com o aumento da idade, sem alterações quanto ao sexo. A maior redução do espaço articular superior, nas mulheres, pode estar relacionada a maior prevalência de artrites nas mulheres, no entanto, como o espaço superior pode erroneamente aparecer reduzido por causa do ângulo vertical de incidência, a determinação de um preciso diagnóstico é questionável. $\mathrm{O}$ aumento da prevalência das alterações morfológicas é esperado, tendo em vista a alta carga na ATM em pacientes com disfunções articulares. Os autores acreditaram que as TR's podem servir como um auxiliar importante no exame e diagnóstico das DTM's.

TUCKER ${ }^{56}$, em 1984, afirmou que uma boa qualidade das TR's é necessária porque a maioria das patologias da ATM ocorrem no pólo lateral e esta técnica mostra melhor esta região, sem distorções ou superposição de outras estruturas anatômicas. Avaliou a tomada transcraniana permitindo variações de angulações horizontais e verticais, sugerindo um ponto de referência reproduzível que possa ser repetido precisamente em futuras avaliações. A angulação vertical utilizada foi de aproximadamente 25 graus em relação ao plano horizontal e 4 a 7 graus com o plano frontal. Duas estruturas são importantes nesta avaliação: a linha petrosa do temporal e o processo clinóide posterior por proximal. A sela túrsica é o referencial usado para localização do processo clinóide. Por causa da utilização de um posicionador de cabeça, permitiu-se uma variação de ângulo horizontal de 0 a 10 graus e uma variação de 21 a 30 graus de angulação vertic al. No estudo, a padronização foi de 25 graus vertical e 4 graus horizontal. Se a angulação é variada, o processo clinóide posterior pode estar superposto à fossa e ao 
côndilo ou, ainda, o pólo medial do côndilo pode estar projetado no espaço articular anterior que poderia ser interpretado como um deslocamento anterior do côndilo. Se a cabeça é inclinada para cima no plano horizontal, o processo clinoíde posterior é projetado anteriormente e a linha petrosa é posicionada mais superiormente. Se a cabeça é inclinada para baixo, a linha petrosa é projetada inferiormente e o processo clinóide posterior é superposto ao côndilo.

AQUILINO et al. ${ }^{1}$, em 1985, investigaram a precisão das radiografias da ATM no relacionamento do côndilo na fossa glenóide com a dimensão relativa do espaço articular. Avaliaram também como os observadores confiavelmente poderiam determinar as dimensões da posição e espaço articular da ATM. Foi selecionado um crânio seco com dentição completa, classe I de Angle e uma aparência normal dos côndilos e fossa. Um suporte de alumínio foi confeccionado para posicionar o crânio de acordo com as exigências radiográficas, de modo que o mesmo se fixasse nos eixos horizontal e vertical. A TR foi usada em três diferentes técnicas. A primeira fase do estudo comparou medidas do espaço articular de modelos de gesso e radiografias entre pares de referência localizados sobre o côndilo e fossa glenóide. Estas marcas foram colocadas sobre o vértex do côndilo equidistante dos pólos lateral e medial e as marcas adicionais foram localizadas $4 \mathrm{~mm}$ anterior e $4 \mathrm{~mm}$ posterior em relação às referências superiores. Impressões com siliconas de adição foram realizadas dos espaços articulares e vazadas em gesso pedra, sendo os modelos recortados, restringindo-os às marcas anteriormente propostas. Cada articulação foi radiografada duas vezes pelas três técnicas propostas. Após estas exposições, um segundo jogo de moldagens foi feito com referências 5,5mm para lateral e $5,5 \mathrm{~mm}$ para medial, centralmente às marcas anteriores. As medidas dos 
espaços articulares foram realizadas mediante o uso de um microscópio. A segunda fase da investigação envolveu avaliação subjetiva dos espaços articulares e do deslocamento do côndilo, por meio de radiografias da ATM, realizadas por estudantes graduados da Universidade da Carolina do Norte. A proporção anteroposterior dos modelos em gesso indicou que o aspecto medial, de ambos os côndilos, foi deslocado posteriormente, a área central deslocada anteriormente e o pólo lateral localizado concentricamente. Quanto às radiografias, o polo lateral foi deslocado posteriormente e nenhum padrão se encontrou consistente na medida dos pólos mediais. Dos 10 estudantes selecionados, 7 julgaram que o côndilo estava deslocado para anterior nas três radiografias avaliadas. Os autores enfatizaram que a posição do paciente e a projeção radiográfica devem ser idênticas quando se deseja mensurar comparativamente os espaços articulares através de radiografias seriadas e nenhuma das técnicas transcranianas se mostrou superior entre si, concluindo que, apesar de úteis, as radiografias não podem ser instrumentos de precisão na mensuração da relação côndilo/fossa e do espaço articular.

LIEDBERG; ROHLIN; WESTESSON ${ }^{27}$, em 1985, estudaram a variação intra e interexaminador da posição condilar em TR's e tomografias sagitais (lateral, medial e central) da ATM. Registraram-se 4 radiografias unilaterais de 31 pacientes aleatórios num total de 124 radiografias, sendo avaliadas por 3 observadores com 4 a 11 anos de experiência em radiografias da ATM, analisando-se se o côndilo estava posicionado para posterior, centralizado ou anterior, em duas oportunidades com intervalo de três meses entre a primeira e a segunda tomadas. A cabeça do paciente foi imobilizada através de um cefalostato. A concordância interexaminadores foi entre 69 e $79 \%$ e intra-examinadores foi entre 81 e $90 \%$. Uma posição avaliada como posterior por um observador nunca foi considerada como anterior em outra 
radiografia por qualquer dos outros dois observadores e vice-versa. Concluíram que as variações e limitações das técnicas radiográficas devem ser consideradas, quando a implicação da posição condilar é discutida.

PULLINGER; HOLLENDER ${ }^{43}$, em 1985, questionaram se as TR's são métodos apropriados de mensuração da posição condilar e se a posição condilar mostrada pelas TR's laterais diferem das mostradas pelas tomografias lineares sagitais, registradas da mesma ATM. Foram selecionados 10 pares de tomografias e TR's, tendo como critério a clareza da visualização das magens e ausência de remodelação óssea. A angulação para as tomografias foi de 20 graus posterior e das TR's de 10 graus posterior e 20 graus cranial. Os métodos de avaliação foram subjetivos, definindo como -2 a posição mais retruída, -1 se posterior, 0 se concêntrico, +1 se anterior e +2 se extremamente anterior. Um segundo método de avaliação também foi utilizado, o qual tratava-se de um método qualitativo, que aplicava a seguinte equação logarítmica para se determinar a posição condilar:

$$
X=\log \text { e } \frac{\text { Medida do espaço articular posterior }}{\text { Medida do espaço articular anterior }}
$$

Através das tomografias, os côndilos se mostraram mais para posterior por meio de análise subjetiva. Nas TR's, o côndilo permaneceu concêntrico utilizando os métodos de centralização da fossa e crista da eminência, assim como pelo método de mensuração linear. Do total, $40 \%$ dos casos foram classificados como concêntricos e $40 \%$ como posteriores nas tomografias, enquanto que $30 \%$ concêntricos e $50 \%$ posteriores nas TR's quando o côndilo foi avaliado via mensuração linear de forma subjetiva do espaço articular, que foi o método preferido recomendado para comparação. A avaliação subjetiva e a mensuração linear expressada pela equação 
logarítmica foram consideradas os métodos de escolha para representar a posição condilar. Uma concordância completa para posição condilar pela avaliação subjetiva foi determinada em $60 \%$ dos pares de TR's e tomografias. Apesar dos dados serem significativos, as tomografias se mostraram mais confiáveis na precisão dos resultados do que as TR's.

PULLINGER et al. ${ }^{45}$, em 1985, propuseram estimar a variabilidade das tomografias lineares da posição normal dos côndilos, em indivíduos jovens assintomáticos sem história de tratamento oclusal ou ortodôntico. Foi selecionada uma amostra aleatória de 26 homens e 20 mulheres. Os dentes foram mantidos em MIH e empregada uma angulação padrão posterior de 20 graus. O escore " 0 " indicou concentricidade, -2 e -1 posição posterior, e +1 e +2 indicando anterior. $\mathrm{O}$ cálculo para se determinar esses valores foi a equação proposta por PULLINGER e HOLLENDER ${ }^{44}$. Valores de concentricidade foram em torno de $50 \%$ a $60 \%$, com exceção à tomada por medial que mostrou $35 \%$ de concentricidade. Os homens mostraram uma posição condilar mais para anterior do que as mulheres, entretanto, a posição mais posterior foi duas vezes maior nas mulheres. Advém desses dados que as mulheres tenham uma maior propensão a ter deslocamentos dos discos, mas, para que se afirme isto, é preciso uma acompanhamento longitudinal, tendo em vista que um tratamento puramente baseado pela análise da posição de concentricidade condilar torna-se bastante arriscado.

PULLINGER; HOLLENDER ${ }^{44}$ publicaram em 1986 a fórmula para cálculo da posição condilar idealizada 2 anos antes, consistindo da seguinte equação: 
Espaço articular posterior - espaço articular anterior $\quad x \quad 100 \%$

Espaço articular posterior + espaço articular anterior

Um valor positivo indicaria que o côndilo estaria posicionado para anterior, nulo representaria a concentricidade e um negativo para posterior.

PULLINGER et al. ${ }^{46}$, em 1986, estudaram se análises tomográficas ofereciam diferenças significativas na posição condilar, quando pacientes eram avaliados dentro dos subgrupos de diagnóstico das DTM's. A amostra constituiu de 106 pacientes com desordens e exames tomográficos da ATM e pacientes do grupo controle assintomáticos. Todos foram tratados por um autor (W.K.S) durante 1 ano, sendo examinados e diagnosticados detalhadamente para, posteriormente, serem classificados em um dos três grupos de diagnóstico: Mialgia, Desarranjos internos e Artrose ou Artrites. Tomografias laterais foram registradas em MIH com 20 graus de angulação posterior. As radiografias foram projetadas num computador com $12.5 \mathrm{x}$ de magnificação usando uma câmera de vídeo conectada ao computador. A posição do côndilo foi determinada baseada na equação descrita por PULLINGER; HOLLENDER ${ }^{44}$. A média da posição foi posterior em todos os grupos de diagnóstico estudados e concêntrico no grupo controle. No grupo de desarranjo, 52,5\% foram posteriores, $40 \%$ concêntricos e 7,5\% anteriores. No grupo da Mialgia, 15,8\% foram posteriores, 78,9\% concêntricos e 5,3\% anteriores. Na categoria das Artroses, $41,25 \%$ foram posteriores, $38,2 \%$ concêntricos e $20,6 \%$ anteriores. A idade foi um fator significativo na descrição da posição condilar, sendo que houve uma tendência do côndilo se posicionar mais para posterior nos pacientes acima de 45 anos. 
HATJIGIORGIS et al. ${ }^{16}$, em 1987, pesquisaram sobre a posição do côndilo em RC na DVO correta, variações da angulação e altura da eminência em pacientes edêntulos, bem como remodelação ou alterações degenerativas nos componentes ósseos da articulação, que poderiam ser detectadas através de tomografias. Dividiram a amostra em dois grupos, o primeiro com 15 pacientes edêntulos e o segundo com 12 jovens classe I de Angle, com ausência de abrasões. Ambos os grupos estavam livres de sinais e sintomas de disfunção. O grupo dentado usou um desprogramador oclusal 24 horas antes da tomada tomográfica, a fim de permitir um relaxamento dos músculos da mastigação e posicionar o côndilo em RC. No grupo edêntulo foram feitas próteses totais em RC na DVO adequada. O centro do côndilo foi relacionado ao centro da fossa glenóide, através do sistema de coordenadas X e Y, sendo o ponto "0" o ponto de intersecção dos eixos X e Y. Os resultados mostraram que as médias de posição condilar medida do centro à fossa foram $X=-0,23 \mathrm{~mm}$ e $\mathrm{Y}=-3,70$. Para o grupo dentado, as médias foram $\mathrm{X}=-0,90 \mathrm{~mm}, \mathrm{Y}=-4,41 \mathrm{~mm}$. Houve, então, uma grande variabilidade da posição no interior da fossa glenóide em RC na DVO. A média dos valores da posição do côndilo para edêntulos revelou uma leve alteração da sua posição para frente e para cima comparando-se o grupo com o grupo dos dentados. Os dados desse trabalho também concluíram que pouca ou nenhuma atividade remodeladora ocorreu sobre a eminência articular, mas no côndilo foi observada uma remodelação da ordem de $63,3 \%$, o que indica que este componente da ATM possui maior remodelação do que qualquer outro componente. Por fim, 13,3\% dos pacientes edêntulos exibiram alterações degenerativas radiograficamente.

PULLINGER et al. ${ }^{47}$, em 1987, estudaram a associação da relação côndilo/fossa, na posição de intercuspidação, com fatores oclusais, numa 
amostra de adultos jovens ( 24 homens e 20 mulheres) livres de sinais e sintomas de DTM's e submetidos a um detalhado exame clínico e questionário. Tomografias lineares foram escolhidas para se avaliar a posição condilar, sendo aplicado um escore de -1 (posterior), 0 (concentricidade) e +1 (anterior). $\mathrm{O}$ cálculo para se determinar os valores foi obtido através da equação proposta por PULLINGER e HOLLENDER ${ }^{44}$. Os parâmetros oclusais para comparação foram as classificações de Angle, overjet e overbite, discrepância entre RC e MIH e linha média dos dentes. Os pacientes classe II de Angle mostraram ser menos concêntricos do que os classe I, sendo os classe II divisão I mais para anterior. As demais características oclusais não apresentaram quaisquer dados significativos com a variação condilar.

SAKURAI et al. ${ }^{52}$, em 1988, investigaram a incidência de DTM's numa população de 220 pacientes edêntulos e avaliaram a possível relação entre sinais-sintomas e determinados fatores clínicos. A média de idade variou de 26 a 94 anos, sendo que 138 do total já possuíam dentaduras e 82 nunca haviam usado. Foi realizada uma entrevista para coleção de dados auxiliares por 4 investigadores. Os sinais e sintomas considerados neste estudo foram dor, ruído, subluxação, dores de cabeça, de ouvido ou nos olhos ou outras dores faciais, desvio na abertura ou fechamento, sensibilidade à palpação articular ou muscular. $\mathrm{O}$ resultado mostrou que 56 pacientes tinham sintomas, mas somente 3 haviam se queixado. Os sintomas mais comuns foram dores de cabeça, do ouvido, dos olhos e dos músculos da face. Um total de 136 pacientes tinham sinais de DTM, principalmente desvio da mandíbula, sensibilidade à palpação e sons articulares. Outro dado relevante foi que pacientes que usavam dentaduras por mais de 6 anos 
tinham mais sinais/sintomas de DTM e que não houve uma correlação da remoção das dentaduras com sinais e sintomas de desordens.

PRETI; FAVA ${ }^{40}$, em 1988, estudaram qual técnica pode ser considerada a mais confiável na determinação da posição condilar e a validade das TR's. Um craniostato permitiu um completo e preciso estudo radiográfico, facilitando a rotação da cabeça no eixo vertical. Com este dispositivo, 10 crânios e 15 pacientes somando um total de 50 ATM's foram selecionados. As tomadas radiográficas foram registradas em MIH através de uma silicona para registro. Impressões com siliconas também foram feitas do espaço articular. Após remoção da silicona, 3 pinos foram postos no topo da impressão com o objetivo de se marcar o longo eixo da articulação. A extensão lateral foi marcada com um quarto pino. A impressão foi vazada em gesso pedra e, após a presa, o modelo foi recortado em fatias de $2 \mathrm{~mm}$ perpendiculares ao $\log$ o eixo. As fatias foram então avaliadas por um completo exame radiográfico que consistiu de exame submentovértex, uma fluoroscopia, duas TR's (uma baseada na radiografia submentovértex e outra na fluoroscopia) e, por fim, executaram-se tomografias em camadas perpendiculares ao longo eixo do côndilo. A posição condilar foi julgada por 3 radiologistas, dividindo-a em anterior, central e posterior. O exame radiográfico processou-se da mesma forma em 15 pacientes e foi avaliado da mesma maneira. A comprovação que se chegou foi que as TR's individualizadas por meio de fluoroscopia podem ser instrumentos úteis para a determinação da posição condilar.

GROSS ${ }^{13}$, em 1988, avaliou a variação na posição condilar como resultado do aumento da dimensão vertical de oclusão, por meio de TR's, sendo selecionados 20 pacientes assintomáticos ( 8 mulheres e 12 homens) 
aleatoriamente. Estes pacientes possuíam uma relação interscuspídica e dimensão estáveis. Para cada paciente, foram feitos 3 registros interoclusais em cera com alturas de $2,5 \mathrm{~mm}, 5 \mathrm{~mm}$ e $10 \mathrm{~mm}$. Um JIG foi confeccionado para que os registros fossem feitos na posição de eixo terminal de rotação, sendo todos os casos manipulados pelo mesmo operador. Foram executadas 4 exposições, 3 nas dimensões dos registros e uma em MIH (primeira exposição). O procedimento de análise sucedeu-se superpondo a primeira exposição com as demais separadamente. Para se quantificar a variação de movimento e de direção do côndilo, foi determinado o ponto superior condilar (PSC). Os resultados mostraram que, numa abertura de $2,5 \mathrm{~mm}$, o desvio do PSC foi de 0,67mm; em 5mm de abertura do PSC foi de $1,17 \mathrm{~mm}$; e em 10mm de abertura a média de desvio do PSC foi de 2,05mm. Menos de 0,5mm de deslocamento do PSC foi considerado como sem variação e nenhuma visível mudança foi notada na posição da imagem condilar nos traçados superpostos. Variações da ordem de 0,5 a $1,5 \mathrm{~mm}$ de deslocamento do PSC foram designadas como leves variações e de difícil visualização para traçado. Quanto à direção, incidência e extensão de deslocamento do PSC, a maioria das variações foram para baixo e para frente em 39,5\% na abertura de $2,5 \mathrm{~mm}, 57,5 \%$ na abertura de $5 \mathrm{~mm}$ e $67,5 \%$ com $10 \mathrm{~mm}$ de abertura. A média de deslocamento do PSC foi de $1,01 \mathrm{~mm} ; 1,65 \mathrm{~mm}$ e $2,73 \mathrm{~mm}$ para abertura 2,5; 5 e 10mm respectivamente. Diante disto, as TR's apresentaram uma variação significativa da posição condilar, sendo que as diferenças poderiam ser atribuídas ao ângulo de suporte, variações da morfologia condilar, eixo de orientação do feixe radiográfico e o efeito da alteração da DVO.

GRAY; QUAYLE; HORNER ${ }^{11}$, em 1991, realizaram um estudo laboratorial, verificando a variação da posição condilar através de TR's da 
ATM de espécimes adultas. A angulação da espécime oscilou de -20 a 20 graus, enquanto que os côndilos variaram entre -2 a 40 graus num plano coronal e a angulação de suporte do raio- x variou entre 20, 25 e 30 graus. Um aparato foi planejado para segurar a espécime e permitir o movimento rotacional medial e lateral no plano sagital. Foram determinados o ponto y, que correspondeu à linha que intercepta o àpice da cabeça do côndilo; linha 1 , que é a extensão horizontal do ponto y em direção à crista da eminência; as linhas 2 a 7 , que são extensões do ponto y em sucessivos incrementos de 30 graus; a linha 8 , que é a extensão da ponta da eminência à margem anterior do côndilo; a linha 9, que é extensão horizontal da margem posterior do côndilo à margem posterior da fossa; a linha 10, desenhada tocando as linhas 2 e 6 formando um triângulo. Todas as medidas envolvendo o aspecto posterior da articulação foram inseguras devido à pobre definição da margem posterior da fossa. As linhas 6, 7 e 9 foram excluídas devido à pobre consistência de seus valores. Grandes variações foram percebidas com as mudanças das angulações na rotação da espécime e suporte. Portanto, comparações através de TR's da posição condilar precisam ter um posicionador de cabeça rígido e confiável para que os resultados possam ter valor.

\section{KNOERNSCHILD; AQUILINO; RUPRECHT ${ }^{25}$, em 1991,} compararam as medidas dos espaços articulares através de tomadas tomográficas lineares e TR's, a fim de se determinar se a posição condilar poderia ser precisamente registrada radiograficamente. Os espaços articulares foram mensurados através de um digitizador sônico de 6 cadáveres intactos, considerando que as dimensões do espaço articular anatômico foi registrada a partir da espessura da impressão em poliéter medida através de um micrômetro. Os resultados mostraram que apenas as 
projeções tomográficas refletiram precisamente a relação côndilo/fossa. Por causa das angulações, os registros das TR's mostraram apenas o terço lateral do côndilo; o espaço anterior e posterior geralmente aparecem menores do que as dimensões anatômicas. Este estudo questionou o uso do espaço articular superior para avaliação da posição condilar, mesmo que as tomografias tenham demonstrado certa precisão na relação côndilo/fossa.

PIRTTINIEMI et al. ${ }^{39}$, em 1991, mensuraram a assimetria condilar utilizando tomografia computadorizada, estando os pacientes em $\mathrm{MIH}$, e verificaram se esta assimetria se correlacionava com certas características oclusais. Foram selecionados 49 pacientes sem história de tratamento ortodôntico e com presença de todos os dentes em bom estado. $\mathrm{O}$ côndilo esquerdo foi mais para anterior e linha média do que o do lado direito. A assimetria dos côndilos se correlacionou com a assimetria oclusal, e indivíduos com más oclusões laterais mostraram mais assimetria dos côndilos. Consideraram que esta má oclusão poderia ter significado clínico quando não ocorresse uma completa adaptação por parte do paciente.

SAKUDA et al. ${ }^{51}$, em 1992, propuseram um novo método de avaliação tridimensional da posição do côndilo em relação à fossa glenóide e investigaram sua aplicação clínica em pacientes submetidos à ortodontia com desordens da ATM. Um posicionador da cabeça foi proposto para estabilizar o procedimento. $\mathrm{O}$ trabalho foi realizado em dois pacientes que possuíam estalido durante a abertura. Com os dentes em MIH, tomadas tomográficas foram feitas, nas quais se encontraram uma posição mais posterior do côndilo direito. A terapêutica aplicada foi a confecção e instalação de uma placa oclusal protrusiva. Após 2 meses usando a placa, uma nova série de tomografias foi realizada onde se visualizou que o côndilo 
direito havia significativamente movimentado para anterior com conseqüente desaparecimento da dor e estalido. Com a diminuição dos sintomas, o tratamento ortodôntico foi iniciado.

ARTUN; HOLLENDER; TRUELOVE ${ }^{2}$, em 1992, testaram a hipótese de que pacientes tratados com extração de dente somente na maxila aumentaria a prevalência de posicionamento posterior do côndilo e avaliaram a relação da posição condilar com sinais e sintomas de desarranjos internos da ATM. Um total de 29 mulheres, após tratamento para classe II de Angle, divisão I, submeteram-se à extração dos pré-molares e 34 mulheres, após tratamento de classe I sem qualquer extração, foram examinadas clinicamente e radiografadas na sequiência da pesquisa. As tomografias em seções lateral, medial e central foram obtidas de cada articulação e mensurações lineares foram feitas, com uma régua milimetrada, da menor distância articular anterior e posterior. A base para os cálculos foi a expressão idealizada por PULLINGER; HOLLENDER ${ }^{40}$. Os resultados não sugeriram que os côndilos estavam mais para posterior em pacientes submetidos à extração de pré- molares, e sim que, no grupo sem extração, os côndilos encontravam-se mais para anterior. Outro dado importante foi que, quando os côndilos estavam para posterior, havia sido diagnosticado clinicamente presença de estalido articular. Os autores afirmaram que a seleção de apenas uma secção tomográfica pode não expressar a verdade sobre a posição condilar.

HONGCHEN; JILIN; NING ${ }^{20}$, em 1992, avaliaram a variação da posição do côndilo na fossa glenóide, os espaços articulares superior, anterior e posterior e a relação entre os rebordos residuais da maxila e mandíbula. Foram analisados 10 (dez) pacientes (6 mulheres e 4 homens) 
totalmente edêntulos, ocluídos em dimensões vertical e horizontal corretas e também sem as próteses, deixando os rebordos mais próximos possível. Utilizaram de TR's com suporte localizado de 25 graus em relação à região parietal superior. Uma folha de acetato foi colocada sobre a radiografia e os traçados do côndilo e da fossa glenóide foram realizados. O método traçado foi baseado nas seguintes linhas guias:

- Linha de referência: desenhada paralela ao plano horizontal de Frankfort e tangente ao aspecto mais superior da fossa glenóide;

- Linha A: a partir do ponto mais alto da fossa glenóide, desenhou-se uma linha perpendicular à linha de referência;

- Linha B: desenhada com 45 graus de inclinação em relação à linha de referência, atravessando a porção mais fina do espaço articular anterior;

- Linha C: desenhada com 45 graus de inclinação em relação à linha de referência, passando através das linhas A e B;

- Linha 1: paralela à linha de referência e tangente ao ponto mais alto do côndilo;

- Linha 2: perpendicular à linha 1 e tangente ao aspecto mais anterior do côndilo;

- Linha 3: paralela à linha 2 e tangente ao aspecto mais posterior do côndilo;

- Linha 4: paralela à linha 1 e numa distância da linha 1 igual àquela vista entre as linhas 2 e 3;

- Linha E-F: paralela à linha de referência e tangente à crista da eminência articular;

- Linha X: no meio e paralela às linhas E-F e linha de referência; 
- Linha Y: perpendicular à linha de referência no ponto onde a linha de referência intercepta o ponto mais alto da fossa glenóide.

Em seguida, as linhas numeradas formaram um quadrado e a intersecção das diagonais do quadrado representam o centro do côndilo. O ponto de intersecção entre os dois eixos $\mathrm{Y}$ e X correspondiam ao centro da fossa glenóide. Os valores dos espaços articulares superior e posterior e a distância do côndilo ao centro da fossa glenóide sobre o eixo Y foram estatisticamente menores na posição edêntula do que na posição de intercuspidação. Os valores médios do espaço articular anterior e a distância entre os dois centros sobre o eixo $\mathrm{X}$ foram maiores na posição edêntula do que em intercuspidação. Este estudo sugeriu que é importante determinar corretamente a DVO e a posição de intercuspidação, não somente pelos valores estéticos e funcionais da dentadura, mas também, para observar a localização que o côndilo ocupa no interior da fossa glenóide, objetivando a prevenção das desordens da ATM.

KAPA et al. ${ }^{22}$, em 1993, avaliaram TR's da ATM, com e sem patologia simulada, comparando-as com imagens por subtração digitalizadas e histogramas da mesma articulação. Cada TR foi tomada, captada por uma câmera CCD (Panasonic WV - C050) e enviadas ao computador. A especificidade e sensibilidade das imagens por subtração foi de 0,83 e 0,76 , respectivamente, em detrimento dos 0,42 e 0,54 das radiografias convencionais. Estas imagens diminuem a superposição de estruturas anatômicas vistas nas radiografias convencionais, graças à utilização do computador que oferece informações adicionais ao diagnóstico. Concluíram que as imagens por subtração têm o potencial de aumentar o campo do 
diagnóstico das TR's para avaliações da cabeça do côndilo, mas questionaram o uso prático desta técnica na clínica diária ou como apenas um instrumento de pesquisa.

MUTO et al. ${ }^{36}$, em 1994, propuseram uma investigação para se determinar a posição anatômica do côndilo na máxima abertura bucal e a relação entre a movimentação anterior ou vertical do côndilo na eminência durante a abertura. Foram tomadas TR's de 86 pacientes. $\mathrm{O}$ ângulo de suporte foi de 25 graus em relação à região parietal superior. Cada radiografia foi recoberta com um papel para que se desenhassem as estruturas anatômicas. As seguintes referências foram utilizadas: S, o ápice posterior da fossa glenóide; E, o ápice da eminência articular; Linha S-E, a extensão da fossa glenóide; F, o ponto que tangencia o aspecto mais superior da fossa glenóide paralelo à linha S-E; C1, o ponto intermediário entre os limites anterior e posterior do côndilo; Linha F-C1, a profundidade da fossa glenóide; C2, ponto paralelo à linha S-E na região que intercepta o ápice do côndilo, quando da abertura máxima de boca. Os resultados mostraram uma média de abertura de boca e extensão dos movimentos laterais maior nos homens do que nas mulheres. Embora a extensão da fossa glenóide esquerda tenha sido semelhante entre homens e mulheres, os valores do lado direito foram maiores nos homens. A profundidade da fossa foi significativamente maior nos homens. O movimento para frente do côndilo na eminência (C1C2) foi de aproximadamente $19,4 \mathrm{~mm}$ nos homens e $18,2 \mathrm{~mm}$ nas mulheres. A distância entre o côndilo e o ápice da eminência na máxima abertura de boca (E-C2) foi de aproximadamente 9,2mm nos homens e 7,8mm nas mulheres. Na posição vertical, o côndilo na maioria dos homens e mulheres estava localizado inferiormente ao ápice da eminência. Concluíram que, na máxima abertura bucal, nenhuma correlação significativa houve entre a 
profundidade da fossa glenóide e o movimento vertical do côndilo na eminência.

PULLINGER; WHITE ${ }^{48}$, em 1995, mensuraram a eficácia dos achados inesperados das tomografias da ATM em pacientes clinicamente agrupados como portadores de mialgia, desarranjos e osteoartrites. Questionário com 73 perguntas e registros em vídeo compuseram o material para avaliação dos observadores com experiência em dores orofaciais e problemas articulares. Os observadores descreveram o que esperavam como achados radiográficos de cada paciente. Após esta etapa, as radiografias foram mostradas aos avaliadores e as variações dos achados esperados e reais foram comparados. A amostra consistiu de 105 pacientes que tinham queixa de dor pré-auricular ou regional, que haviam sido requisitados para radiografias da ATM e que consentiram em participar do estudo. Com base nos achados clínicos e na história do paciente, os avaliadores julgaram que seriam necessárias tomadas tomográficas em $91 \%$ dos casos para uma maior precisão diagnóstica. Na avaliação dos observadores, esperou-se menos alterações ósseas em pacientes com mialgia e desarranjos internos do que com osteoartrites, o que veio a se confirmar com as radiografias. Quanto à posição condilar, esperava-se que a relação côndilo/fossa fosse mais posterior em pacientes com desarranjos e osteoartrites do que no grupo com mialgia, entretanto esta expectativa só foi significativa para as osteoartrites. Finalizaram afirmando que as tomografias muito freqüentemente são produtivas quando os pacientes se queixam de dores e disfunção pré auriculares, oferecendo adicionais informações além do que a história e exame clínico podem mostrar. 
NILNER; PETERSSON ${ }^{37}$, em 1995, avaliaram a hipótese de que o efeito do tratamento nos pacientes com DTM não é influenciado pela posição condilar, assimetria, ângulos e variações ósseas estruturais. Os 80 pacientes foram atendidos por um único Cirurgião-Dentista que realizou questionários, entrevistas e exame clínico do sistema estomatognático. $\mathrm{O}$ grau de severidade dos sintomas encontrados variou de 1 (mínimo) a 5 (muito severo). No exame clínico, avaliaram-se os movimentos mandibulares, sensibilidade dos músculos e ATM à palpação, ruídos articulares e oclusão. O diagnóstico clínico foi feito a partir das orientações da Academia Americana de Dor Orofacial, independentemente dos achados radiográficos. Tomografias laterais em $\mathrm{MIH}$ foram realizadas em 58 pacientes antes e 42 após o tratamento, sendo também feitas tomadas panorâmicas em 60 indivíduos antes do tratamento, todas interpretadas por um observador. Houve a recusa de 20 pacientes antes e 38 após o tratamento, em relação às exposições radiográficas. A média de escore ao questionamento verbal foi de 4 (severa) antes e de 2 (leve) após tratamento. As terapias propostas foram essencialmente conservadoras, oscilando entre aconselhamento e informação, placas oclusais, ajustes, drogas, próteses. Em apenas um caso, houve indicação para cirurgia. A média de angulação horizontal para desordens musculares foi de 20,5 graus e de 25,8 graus para desordens articulares. A assimetria condilar foi maior neste último grupo. A posição do côndilo não tinha impacto como conseqüência do tratamento, visto que a maioria dos pacientes não variou a posição condilar após terapia. Resultados semelhantes foram encontrados nas alterações ósseas, nas quais não houve modificação após terapias. A posição do côndilo na fossa, como prática comum, não foi determinante na escolha do tratamento, concluindo ser de pouco valor no manejo de pacientes de DTM com melhor 
prognóstico. No entanto, o deslocamento condilar pode ser um fator de risco no desenvolvimento da DTM.

COHLMIA et al. ${ }^{8}$, em 1996, estudaram a relação morfológica do côndilo e fossa antes do tratamento ortodôntico, em pacientes portadores de má oclusão e distúrbios musculares na face. Foram examinados 232 pacientes, 95 homens e 137 mulheres, divididos nos diversos grupos de classificação de Angle, dos quais se obtiveram modelos, radiografias laterais cefalométricas e tomografias. A média de abertura bucal foi de $46 \mathrm{~mm}$ e de extensão lateral direita foi de $9,8 \mathrm{~mm}$ e esquerda de $10,0 \mathrm{~mm}$. Somente um paciente registrou sensibilidade na articulação sem palpação. Dados de estalidos simples foram encontrados em 13 casos do lado direito e 10 do lado esquerdo, assim como 5 do lado direito e 9 do lado esquerdo foram diagnosticados como estalido recíproco. Crepitação foi notado unilateralmente em dois pacientes e bilateral em apenas um. As referências para o estudo radiográfico foram feitas através de linhas:

1) Linha 1- Tangente ao ponto mais superior da fossa glenóide (FS) e paralelo à borda superior do filme radiográfico;

2) Linha 2- Paralela à linha 1, sendo localizado no aspecto superior do côndilo (CS);

3) Linha AC- Parte do ponto SF, tangenciando o aspecto anterior do côndilo;

4) Linha PC-Parte do ponto SF, tangenciando o aspecto posterior do côndilo;

5) Linhas $\mathrm{AF}$ e $\mathrm{PF}$ - Linhas perpendiculares a $\mathrm{AC}$ e $\mathrm{PC}$, interceptando os pontos anterior e posterior da fossa glenóide, respectivamente; 
6) Linha AS - Através do ponto AF foi traçada uma linha paralela à linha $\mathrm{AC}$, denominada de inclinação da eminência;

7) Linha 3- Paralela a linha 2 através do ponto mais convexo do aspecto anterior da cabeça do côndilo;

8) Linha AE- $\mathrm{O}$ aspecto mais inferior da crista da eminência articular.

Através dessas referências, pôde-se determinar os espaços articulares anterior, posterior e superior, além da espessura da cabeça do côndilo, altura vertical da fossa articular e posição condilar pela equação proposta por PULLINGER; HOLLENDER ${ }^{44}$. Os homens mostraram resultados significativamente maiores apenas nas dimensões dos espaços articulares superiores de ambas as articulações, sendo que os adultos apresentaram menores espaços articulares posteriores direito e esquerdo e os côndilos foram posicionados mais posteriormente. A média do espaço articular anterior foi de $2,51 \mathrm{~mm}$ direito e $2,69 \mathrm{~mm}$ esquerdo e a média do espaço posterior foi de $2,89 \mathrm{~mm}$ direito e $2,63 \mathrm{~mm}$ esquerdo. Baseado nesses achados, os autores afirmaram que o côndilo esquerdo se posicionava mais anterior do que o direito. $\mathrm{O}$ lado esquerdo teve um espaço articular superior mais largo com cerca de $3,44 \mathrm{~mm}$ contra $3,23 \mathrm{~mm}$ e um ângulo da eminência maior (58.01 graus x 55.10 graus). Quanto às classificações de Angle, os pacientes classe III de Angle apresentaram o côndilo mais para anterior do que nas outras classes.

HESSE et al. ${ }^{19}$, em 1997, propuseram que a correção de mordidas cruzadas posteriores, através da expansão dos ossos maxilares, estivesse associada com a posição condilar e relacionamentos oclusais. O método base para cálculo da posição condilar foi o proposto por PULLINGER; 
HOLLENDER ${ }^{44}$. Avaliações pré e pós-tratamento foram disponíveis em 22 pacientes, nos quais revelaram que os côndilos se movimentaram para posterior e superior no lado sem mordida cruzada, antes e após tratamento. Nenhuma diferença significativa foi observada em relação ao lado que havia a mordida cruzada. O espaço articular superior foi maior no lado que não houve mordida cruzada antes do tratamento e maior após tratamento, no lado com mordida cruzada. O côndilo se mostrou mais para anterior no lado sem alteração antes da terapia e similar em ambos lados após tratamento. A relação do molar e canino estavam mais para classe II antes do tratamento e semelhantes, após tratamento de ambos os lados, além de uma significativa redução de desvio da linha média ao final da terapia.

EKBERG et al. ${ }^{9}$, em 1998, estudaram a relação côndilo/fossa em pacientes com DTM's inflamatórias (capsulites e sinovites), tratadas com placas estabilizadoras, e em um grupo controle que utilizou uma placa ortodôntica com grampos sobre os dentes superiores, sem alterar a relação intermaxilar num estudo duplo-cego. Foram selecionados 58 pacientes, sendo entregues separadamente ao grupo de tratamento e controle as devidas placas, por um período de 10 semanas. Foram registradas TR's e tomografias na avaliação deste trabalho. Foi proposto um escore de 0 (extrema melhora) a 5 (extrema piora) dos sintomas, sendo julgados como insucessos a variação de 3 a 5. Nos pacientes que relataram melhora no tratamento, houve uma significativa variação da posição condilar no grupo em tratamento quando comparado com o grupo controle, o que explica o maior alívio dos sintomas da disfunção.

RAUSTIA et al. ${ }^{49}$, em 1998, analisaram o efeito da edentação sobre o tamanho da mandíbula e relação côndilo/fossa, por meio de 
comparação entre as radiografias roetgnogramas-cefalométricas e tomografias computadorizadas, numa amostra de 20 pacientes edêntulos advindos da própria faculdade de Oulu, Finlândia. A média de uso das próteses foi de 20 anos. O grupo controle consistiu de 16 estudantes da faculdade com dentição completa. As radiografias foram executadas na posição de $\mathrm{MIH}$, sempre no mesmo equipamento. Os resultados indicaram que tanto a posição condilar quanto a fossa glenóide estavam localizadas mais para anterior nos pacientes edêntulos e que, estes dados, se acentuavam quanto maior o tempo em que o paciente possuía os pares de dentadura.

WILLIAMS ${ }^{65}$, em 1998, estudou a posição condilar prétratamento e as variações pós-tratamento, por meio de tomografias de pacientes com DTM's. Na história dos pacientes, incluíam: dor aos músculos da mastigação, sons articulares, contatos oclusais interferentes e limitação nos movimentos excursivos. Um total de 40 pacientes foram selecionados e submetidos a tratamento por meio de placas oclusais e/ou ortodontia (10 com placa, 15 ortodontia e $15 \mathrm{com}$ placa antes da ortodontia). As tomografias foram tomadas em $\mathrm{MIH}$, sendo que o segundo registro ocorreu 1.3 a 13.7 anos após tratamento. Os pontos de referência selecionados para verificação da posição condilar foram: (a) o ponto mais inferior da eminência articular, (b) a ponta mais posterior e ápice da fossa glenóide e (c) um ponto no centro da fossa glenóide. Dos 80 côndilos examinados antes do tratamento, 23 estavam para posterior, 3 para anterior e 54 centralizados. Nenhuma variação ocorreu após o tratamento, o que suporta a idéia de que a posição de não concentricidade dos côndilos pode ser normal e, por isso, a posição do côndilo não deve ser o único meio de diagnóstico das desordens intrarticulares. 
A posição dos côndilos vêm sendo bastante estudada, no entanto, há ainda controvérsias a respeito de uma localização ideal que estes devam assumir. Por isso, uma avaliação criteriosa sobre a posição condilar em desdentados totais torna-se imperiosa, objetivando o conhecimento mais aprofundado desses achados 
3- PROPOSIÇÕES 


\section{3- PROPOSIÇÕES}

Baseado na exposição dos trabalhos citados, propusemo-nos a :

(1) Identificar a relação entre as ATM's de pacientes edêntulos com suas PT's novas ocluídas na DVO e RC corretas;

(2) Avaliar a variação da posição condilar na fossa glenóide antes e após restabelecimento da DVO e RC com as novas próteses, através de planigrafias laterais da ATM;

(3) Correlacionar possíveis sinais e sintomas de DTM com a (s) posição (ões) do côndilo no interior da fossa glenóide;

(4) Correlacionar a variação da DVO com os deslocamentos condilares após instalação das PT's novas. 


\section{4- MATERIAL E MÉTODOS}

Um total de 12 pacientes, sendo 8 do sexo feminino e 4 do sexo masculino, com a idade variando de 53 a 90 anos (média de 65,9 anos) todos com dentaduras duplas foram selecionados na clínica de Prótese Total da Faculdade de Odontologia de Bauru, da Universidade de São Paulo (FOBUSP).

Os pacientes selecionados necessariamente faziam uso de PT superior e inferior, sem a predileção por sexo ou idade. Não foram excluídos da amostra quaisquer pacientes que apresentassem sons articulares, sensibilidade dolorosa muscular ou restrição de abertura ou movimentos excursivos mandibulares. O tempo de uso das dentaduras a serem trocadas variou entre 4 a 40 anos, com média de 13,66.

Um questionário contendo abordagens anamnésicas, exame clínico dividido em avaliação da ATM e exame muscular, e exame radiográfico foi realizado, por um mesmo examinador, com a finalidade de coletar dados gerais e locais pertinentes à pesquisa desenvolvida. Houve a preocupação de não induzir nenhum tipo de resposta aos pacientes.

O período de avaliação dos pacientes equivaleu ao período letivo de 1 semestre dos alunos do curso de graduação, sendo registradas duas radiografias por paciente, uma com as dentaduras em uso (antigas) e depois com as dentaduras novas. Todos os pacientes do grupo amostral estavam cientes de que seriam avaliados não só para o tratamento de reposição, mas também com finalidade de pesquisa. 
O registro da DVO antiga e nova foi executada pelos próprios alunos sob a supervisão direta dos professores responsáveis, através do método do compasso de Willis, associada aos métodos da deglutição, fonético e perfil facial.. Para obtenção da relação cêntrica, o método utilizado consistiu da manipulação guiada.

Obtidas as planigrafias através do aparelho Rotograph Plus (Kodak Dental film/ T-Mat; 12,7 x 30,5 cm; $75 \mathrm{KV} / 5 \mathrm{seg} 20$ decseg), do Departamento de Estomatologia, Disciplina de Radiologia da FOB USP, as mesmas foram digitalizadas e aumentadas em $1600 \%$, no programa de imagens computadorizada Corel Draw 8. As planigrafias foram escolhidas, uma vez que permitem a padronização da técnica radiográfica. Todas as tomadas radiográficas foram realizadas no mesmo equipamento, por pósgraduandos em Diagnóstico Bucal e técnicos em radiologia devidamente instruídos quanto à necessidade de visualização da cavidade articular e acompanhadas pelo pesquisador .

Para a mensuração da variação condilar, o método utilizado foi o idealizado por PULLINGER; HOLLENDER ${ }^{44}$ baseado na seguinte equação:

$$
\begin{aligned}
& \frac{\mathrm{P}-\mathrm{A}}{\mathrm{P}+\mathrm{A}} \times 100, \\
& \text { onde, } \mathrm{P}=\text { Distância interarticular posterior e } \\
& \mathrm{A}=\text { Distância interarticular anterior. }
\end{aligned}
$$


A posição condilar foi expressada como positiva (+) para deslocamentos anteriores, negativa (-) para deslocamentos posteriores e nula (0) para concentricidade condilar.

A análise estatística utilizada foi essencialmente descritiva, com exceção ao coeficiente de correlação de Pearson, realizado entre a variação das DVO's e os deslocamentos condilares.

A anamnese e os exames clínicos e radiográficos estão detalhados a seguir. 


\section{UNIVERSIDADE DE SÃO PAULO \\ FACULDADE DE ODONTOLOGIA DE BAURU}

Nome: Data de nascimento:

Endereço: Bairro:

Cidade: Estado: CEP: Fone residencial:

Nome do responsável:

Endereço de trabalho: Fone trabalho:

\section{ANAMNESE}

SIM NÃO ÀS VEZES

1. Você sente dificuldade em abrir a boca?

2. Você sente dificuldade em movimentar sua mandíbula para os lados?

3. Você sente desconforto ou dor muscular ao mastigar?

4. Você sente dores de cabeça com freqüência?

5. Você sente dores no pescoço e/ou ombros?

6. Você sente dores de ouvido ou próximo a ele?

7. Você percebe algum ruído na ATM?

8. Você considera sua mordida "normal"?

9. Você usa apenas um lado de sua boca para mastigar?

10. Você sente dores na face ao acordar?

11. Você se considera uma pessoa tensa?

12. Há dificuldade fonética após o uso da nova dentadura?

13. Você apresenta algum dos seguintes hábitos?

$\begin{array}{ll}\text { Ranger dentes } & \text { Mascar chicletes } \\ \text { Apertar dentes } & \text { Uso contínuo de telefone } \\ \text { Morder unhas } & \text { Uso contínuo do computador }\end{array}$

14. Quantas dentaduras já usou?

nenhuma

uma

duas

mais de duas 
15. Remove alguma das próteses antes de dormir?

$$
\begin{array}{ll}
\text { inferior } & \text { superior } \\
\text { ambas } & \text { nenhuma }
\end{array}
$$

16 Há quanto tempo usa as atuais dentaduras?

\section{Revisão dos sistemas:}

$\begin{array}{lllll} & \text { Negativo } & \text { Positivo } & \text { Negativo } & \text { Positivo } \\ \text { Cardiovascular } & - \text { Endócrino } & - & - \\ \text { Gastrointestinal/Fígado } & - \text { Respiratório } & - & - \\ \text { Musculoesqueletal } & - & & - & -\end{array}$

\section{EXAME CLÍNICO}

1. AVALIAÇÃO DA ATM:

a) Movimentação:

DOR

ABERTURA MÁXIMA $\mathrm{mm}$

(incluindo trespasse)

LATERALIDADE DIREITA $\mathrm{mm}$

LATERALIDADE ESQUERDA $\mathrm{mm}$

PROTRUSÃO $\mathrm{mm}$

ABERTURA: Simétrica

Desvio:

Direita

Esquerda

Deflexão:

Direita

Esquerda 
b) Ruídos articulares:

ABERTURA

ESTALIDO:

Direito

Esquerdo

Direito

Direito

HIPERMOBILIDADE:

c) Palpação da ATM:
FECHAMENTO

Direito Esquerdo

\begin{tabular}{|l|l|l|}
\hline & Direita & Esquerda \\
\hline Aspecto lateral & & \\
\hline Aspecto posterior & & \\
\hline
\end{tabular}

\section{EXAME MUSCULAR:}

\section{Temporal}

Anterior

Médio

Posterior

DIREITO
DIREITO

ESQUERDO
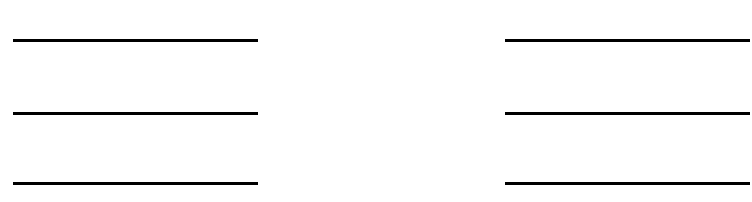

ESQUERDO

\section{Masseter superficial}

Origem

Médio

Posterior

\section{Masseter profundo}

Digástrico posterior

Esternocleidomastoídeo

Trapézio (superior) 


\section{EXAME RADIOGRÁFICO}

Data do exame inicial:

Data do exame final:

ATM DIREITA

MEDIDAS:

Anterior:

$\mathrm{mm}$

Posterior:

$\mathrm{mm}$

ALTERAÇÕES MORFOLÓGICAS:

Não $\quad$ Moderada Severa

CONCENTRICIDADE:

$$
\mathrm{x} 100 \%=
$$

Concêntrico

Posterior

Anterior
ATM ESQUERDA

MEDIDAS:

Anterior: $\mathrm{mm}$

Posterior: $\mathrm{mm}$
ALTERAÇÕES MORFOLÓGICAS:

Não Moderada Severa

$\mathrm{x} 100 \%=$

Concêntrico

Posterior

Anterior

\section{RELAÇ̃̃O CÔNDILO - DIMENSÃO VERTICAL DE OCLUSÃO}

DVO Antiga Posição condilar lado direito lado esquerdo

DVO Nova Posição condilar lado direito lado esquerdo 


\section{5- RESULTADOS}

Os resultados basearam-se nos dados coletados de uma ficha clínica/anamnésica e da avaliação da posição condilar, obtida por meio de planigrafias laterais da ATM, utilizando a equação proposta por PULLINGER; HOLLENDER ${ }^{44}$ :

$$
\frac{\mathrm{P}-\mathrm{A}}{\mathrm{P}+\mathrm{A}} \times 100
$$

Onde, $\mathrm{P}=$ Distância interarticular posterior

$\mathrm{A}=$ Distância interarticular anterior.

Dos dados contidos no questionário anamnésico, pôde-se constatar que, dentre os pacientes que compuseram a amostra, 5 (cinco) consideraramse tensos, 3 (três) afirmaram que apertavam os dentes e 1 (um) relatou hábito onicofágico. Em relação ao uso das dentaduras, verificou-se que 6 indivíduos utilizaram dois pares de dentadura, 4 apenas 1 par e 2 pacientes já tinham usado mais de dois pares.

Quando questionados a respeito da remoção das próteses ao dormir, os resultados mostraram que 6 dos examinados não retiravam nenhuma das dentaduras para dormir, 4 removiam as duas e 2 retiravam apenas a prótese inferior.

Quanto ao tempo de uso do último par de dentaduras que portavam, 7 pacientes relataram que usavam a mais de 10 anos, enquanto 
que 4 permaneciam com as mesmas dentro de um intervalo de 5 a 10 anos e 1 usava a menos de 5 anos.

Concluindo a parte anamnésica, apenas 2 pacientes queixaram-se de dificuldade fonética após a instalação do novo par de próteses e nenhum dado foi significativo no tópico de revisão dos sistemas da ficha clínica.

O exame clínico foi dividido em avaliação das ATMss e músculos da face. $\mathrm{Na}$ avaliação articular, a abertura máxima (incluindo o trespasse) variou de 39 a 55mm, sendo que, nos movimentos excêntricos, protrusivos e lateral direito, oscilaram entre 3 a $9 \mathrm{~mm}$, enquanto a variação da lateralidade esquerda foi de 4 a $10 \mathrm{~mm}$.

$\mathrm{Na}$ avaliação dos ruídos articulares, através da palpação, constatou-se crepitação bilateral em 3 pacientes, estalido recíproco unilateral apenas em um indivíduo e estalido simples em 3 outras articulações ( 2 do lado esquerdo e 1 do lado direito).

Apenas um paciente se mostrou com pontos dolorosos no exame à palpação articular e muscular. Em outras dois pacientes assintomáticos, foram identificados pontos sensíveis à palpação no músculo temporal, de grau leve, assim como no aspecto lateral e posterior da ATM. Os demais não apresentaram quaisquer sintomas dolorosos.

\section{Análise subjetiva da posição condilar}

A primeira tomada radiográfica dos 12 pacientes registrou que os côndilos estavam situados mais para anterior em todo o grupo da amostra. 
A partir da observação dos dados da primeira tomada radiográfica, procedeu-se a análise da segunda tomada, com os pacientes portando pares de próteses totais novas, nas quais as distâncias verticais e horizontais haviam sido restabelecidas. Dentre os 12 pacientes, houve um deslocamento bilateral para posterior em 8 deles, deslocamento para anterior em apenas 1 indivíduo; em 2, observou-se deslocamento alternado (côndilo direito para anterior e esquerdo para posterior ou vice-versa) e, em um único paciente, não houve alteração da posição. Verificou-se que o deslocamento para posterior estava presente em 18 côndilos (75\%), para anterior em 4 outros $(16,7 \%)$ e a percepção de imutabilidade de deslocamento em apenas 2 côndilos $(8,3 \%)$.

Dos 18 côndilos que se deslocaram para posterior, 6 assumiram uma posição bem próxima da concentricidade, 11 permaneceram localizados anteriormente e 1 se deslocou para posterior.

Foi realizado o coeficiente de correlação de Pearson entre a variação da DVO e o deslocamento condilar, obtendo-se $r=0,46$ e $p=0,130$ para o côndilo direito e $r=0,20$ e $p=0,539$ para o côndilo esquerdo. Em ambos os casos, a correlação não foi estatisticamente significativa.

As tabelas 1, 2 e 3 demonstram os valores das posições condilares, dos deslocamentos condilares, obtidos com o auxílio do programa de imagem Corel Draw 8, e distâncias verticais antes e após a instalação das próteses novas. 


\begin{tabular}{|c|c|c|c|c|c|c|c|c|}
\hline \multirow[t]{3}{*}{ Pacientes } & \multicolumn{4}{|c|}{ PRÓTESE ANTIGA } & \multicolumn{4}{|c|}{ PRÓTESE NOVA } \\
\hline & \multicolumn{2}{|c|}{ Côndilo Direito } & \multicolumn{2}{|c|}{ Côndilo Esquerdo } & \multicolumn{2}{|c|}{ Côndilo Direito } & \multicolumn{2}{|c|}{ Côndilo Esquerdo } \\
\hline & Anterior & Posterior & Anterior & Posterior & Anterior & Posterior & Anterior & Posterior \\
\hline 1 & 1,80 & 3,16 & 1,69 & 4,52 & 2,71 & 3,49 & 2,59 & 5,08 \\
\hline 2 & 1,71 & 2,48 & 2,20 & 4,52 & 1,86 & 2,53 & 2,20 & 5,20 \\
\hline 3 & 1,65 & 2,14 & 1,75 & 5,88 & 1,36 & 2,48 & 1,52 & 5,99 \\
\hline 4 & 1,69 & 2,48 & 2,37 & 5,31 & 2,14 & 2,15 & 1,13 & 1,08 \\
\hline 5 & 2,37 & 3,27 & 2,54 & 4,01 & 2,73 & 2,14 & 2,71 & 3,95 \\
\hline 6 & 1,92 & 3,39 & 1,69 & 3,39 & 1,65 & 1,76 & 1,69 & 3,12 \\
\hline 7 & 0 & 3,61 & 0,84 & 1,69 & 0 & 3,16 & 0,96 & 2,03 \\
\hline 8 & 1,64 & 3,44 & 2,20 & 1,69 & 2,14 & 3,39 & 1,58 & 3,09 \\
\hline 9 & 1,52 & 3,10 & 1,35 & 5,53 & 1,35 & 4,29 & 1,80 & 4,86 \\
\hline 10 & 2,14 & 3,39 & 1,24 & 1,69 & 1,76 & 2,51 & 2,14 & 2,11 \\
\hline 11 & 1,46 & 3,50 & 1,01 & 3,95 & 2,08 & 2,26 & 1,97 & 4,40 \\
\hline 12 & 1,69 & 3,84 & 2,03 & 3,72 & 2,16 & 2,01 & 2,19 & 3,35 \\
\hline MÉDIA & 1,63 & 3,15 & 1,74 & 3,82 & 1,82 & 2,68 & 1,87 & 3,68 \\
\hline Mínima & 0 & 2,14 & 0,84 & 1,69 & 0 & 1,76 & 0,96 & 1,08 \\
\hline Máxima & 2,37 & 3,84 & 2,54 & 5,88 & 2,73 & 4,29 & 2,71 & 5,99 \\
\hline $\begin{array}{l}\text { Desvio } \\
\text { Padrão }\end{array}$ & 0,57 & 0,51 & 0,54 & 1,48 & 0,72 & 0,74 & 0,53 & 1,48 \\
\hline
\end{tabular}

Tabela 1 - Posições condilares antes e após instalação das PT’s novas, mensuradas por meio do programa de imagem Corel Draw 8. 


\begin{tabular}{|c|c|c|c|c|c|c|}
\hline \multirow[t]{2}{*}{ Pacientes } & \multicolumn{2}{|c|}{ Côndilo Direito } & \multirow[b]{2}{*}{ Variação } & \multicolumn{2}{|c|}{ Côndilo Esquerdo } & \multirow[b]{2}{*}{ Variação } \\
\hline & Prótese Antiga & Prótese Nova & & Prótese Antiga & Prótese Nova & \\
\hline 1 & 0,27 & 0,12 & $-0,15$ & 0,45 & 0,32 & $-0,13$ \\
\hline 2 & 0,17 & 0,15 & $-0,02$ & 0,34 & 0,40 & 0,06 \\
\hline 3 & 0,12 & 0,29 & 0,17 & 0,54 & 0,59 & 0,05 \\
\hline 4 & 0,18 & 0 & $-0,18$ & 0,38 & $-0,02$ & $-0,40$ \\
\hline 5 & 0,15 & $-0,14$ & $-0,29$ & 0,22 & 0,18 & $-0,04$ \\
\hline 6 & 0,27 & 0,03 & $-0,24$ & 0,33 & 0,29 & $-0,04$ \\
\hline 7 & 1 & 1 & 0 & 0,33 & 0,33 & 0 \\
\hline 8 & 0,35 & 0,19 & $-0,16$ & 0,13 & 0,32 & 0,19 \\
\hline 9 & 0,34 & 0,29 & $-0,05$ & 0,60 & 0,45 & $-0,15$ \\
\hline 10 & 0,22 & 0,17 & $-0,05$ & 0,15 & 0 & $-0,15$ \\
\hline 11 & 0,41 & 0,04 & $-0,37$ & 0,59 & 0,38 & $-0,19$ \\
\hline 12 & 0,38 & $-0,03$ & $-0,41$ & 0,29 & 0,20 & $-0,09$ \\
\hline MÉDIA & 0,32 & 0,17 & $-0,14$ & 0,36 & 0,28 & $-0,07$ \\
\hline Mínima & 0,12 & $-0,14$ & $-0,41$ & 0,13 & $-0,02$ & $-0,40$ \\
\hline Máxima & 1,00 & 1,00 & 0,17 & 0,60 & 0,59 & 0,19 \\
\hline $\begin{array}{l}\text { Desvio } \\
\text { Padrão }\end{array}$ & 0,23 & 0,28 & 0,16 & 0,15 & 0,17 & 0,15 \\
\hline
\end{tabular}

Tabela 2- Variações de deslocamentos condilares após a instalação das PTS novas mensuradas por meio do programa de imagem Corel Draw 8 


\begin{tabular}{|c|c|c|c|c|c|}
\hline PACIENTES & DIMENSÃO. & DIMENSÃO & VARIAÇÃO & \multicolumn{2}{|c|}{ Deslocamento Condilar } \\
\cline { 5 - 6 } & ANTIGA & NOVA & & DIREITO & ESQUERDO \\
\hline 1 & 60 & 64 & 4 & $-0,15$ & $-0,13$ \\
\hline 2 & 48 & 51 & 3 & $-0,02$ & 0,06 \\
\hline 3 & 51 & 54 & 3 & 0,17 & 0,05 \\
\hline 4 & 44 & 46 & 2 & $-0,18$ & $-0,40$ \\
\hline 5 & 43 & 45 & 2 & $-0,29$ & $-0,04$ \\
\hline 6 & 58 & 61 & 3 & $-0,24$ & $-0,04$ \\
\hline 7 & 48 & 52 & 4 & 0 & 0 \\
\hline 8 & 41 & 42 & 1 & $-0,16$ & 0,19 \\
\hline 9 & 45 & 46 & 1 & $-0,05$ & $-0,15$ \\
\hline 10 & 41 & 42 & 1 & $-0,05$ & $-0,15$ \\
\hline 11 & 42 & 51 & 9 & $-0,37$ & $-0,19$ \\
\hline 12 & 47 & 52 & 5 & $-0,41$ & $-0,09$ \\
\hline
\end{tabular}

Tabela 3- Relação entre as variações da DVO e deslocamentos condilares, após instalação das PT's novas. O registro da DVO foi realizado através do compasso de Willis e as variações condilares por intermédio do programa de imagem Corel Draw 8. 


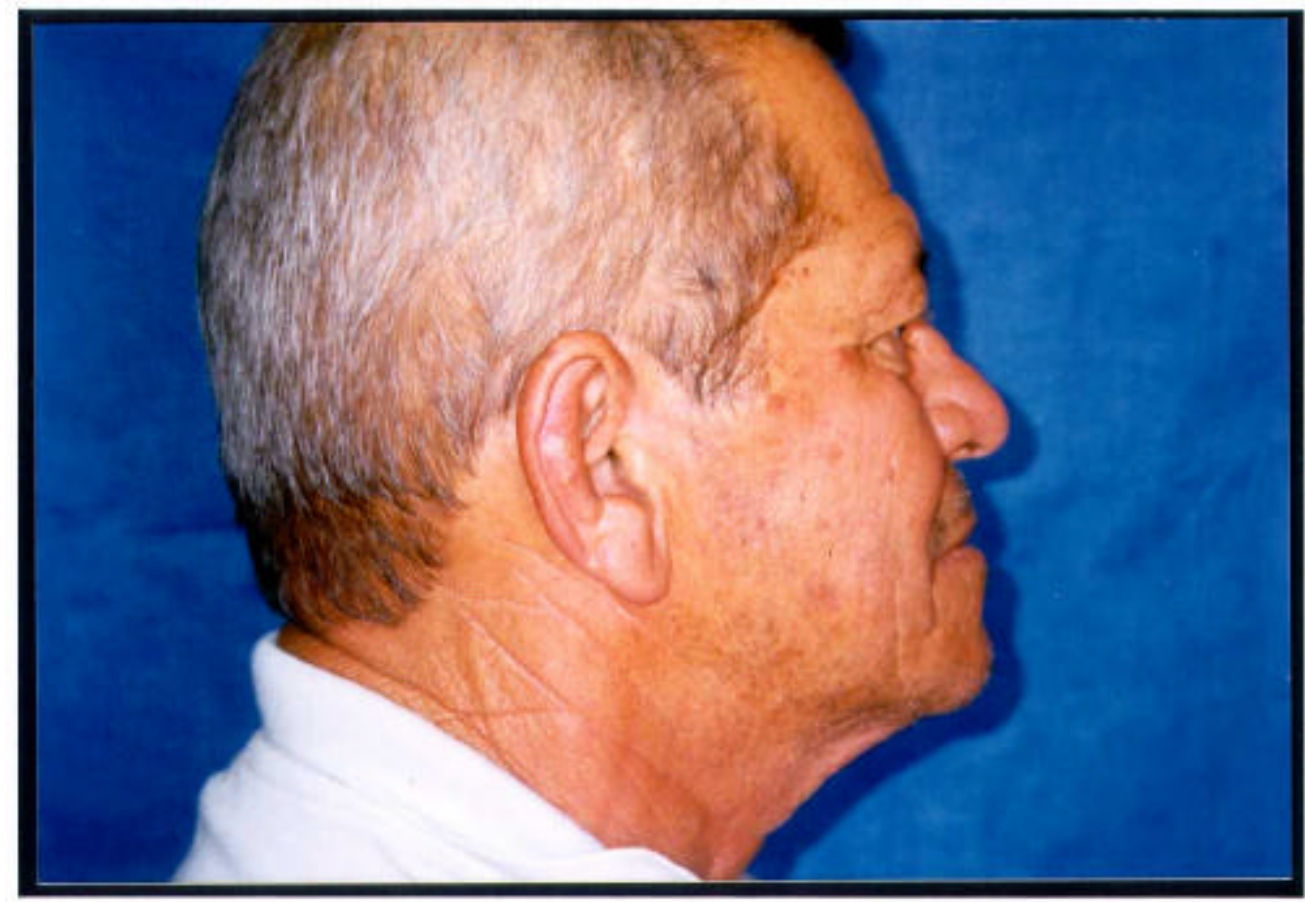

1- Vista lateral do paciente com a prótese antiga.

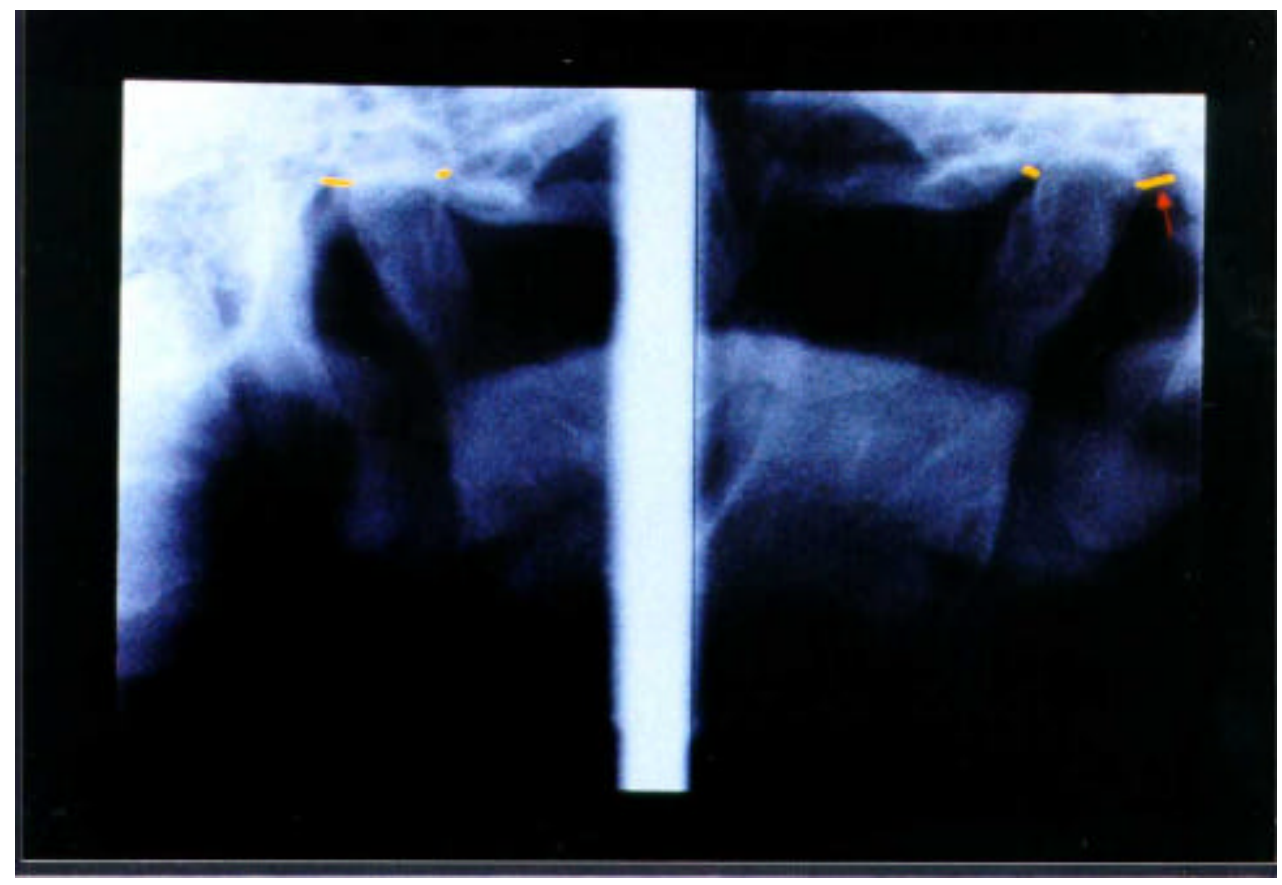

1.1-Radiografia mostrando a posição condilar com a prótese antiga. 


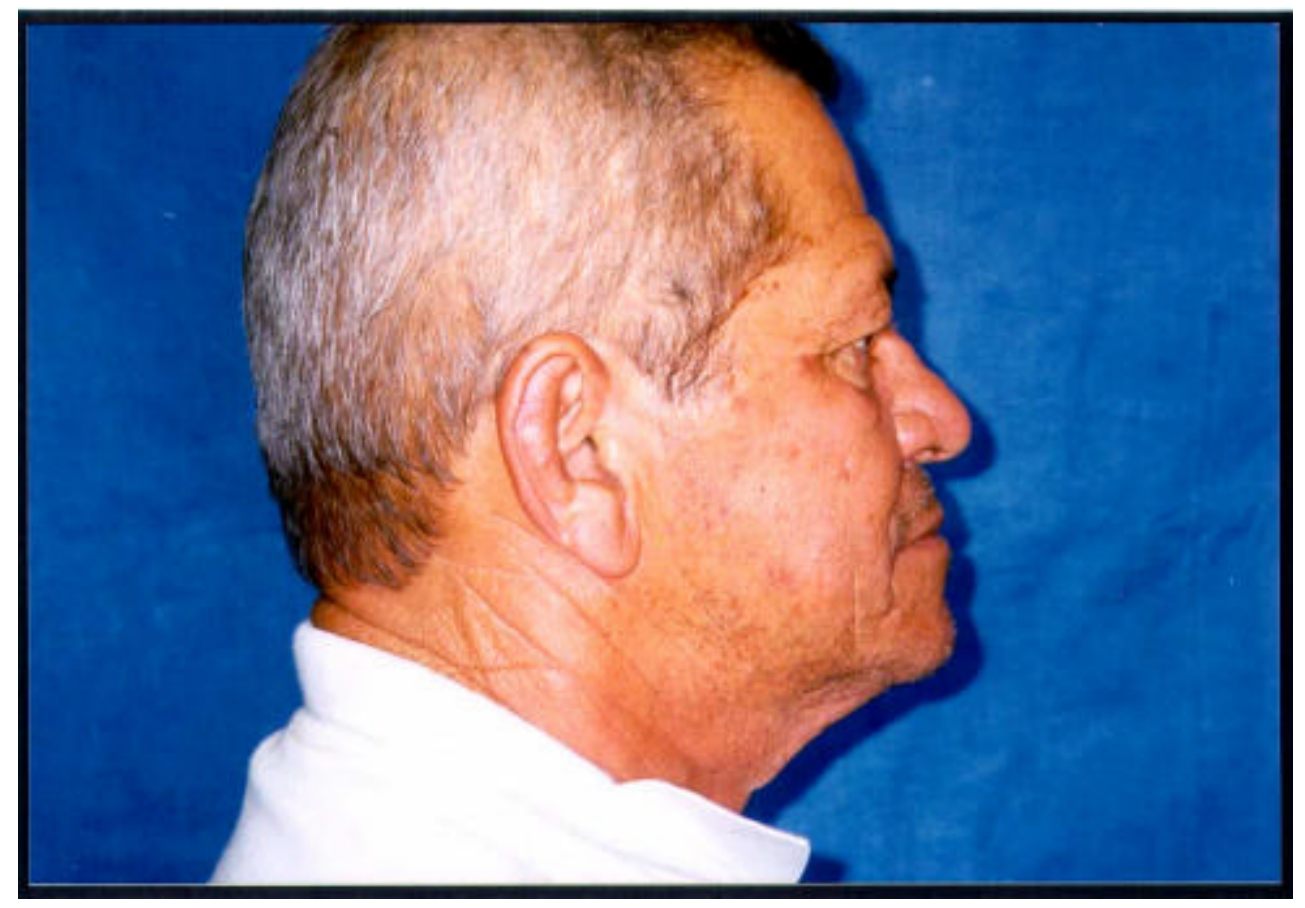

2- Vista lateral do paciente com a prótese nova.

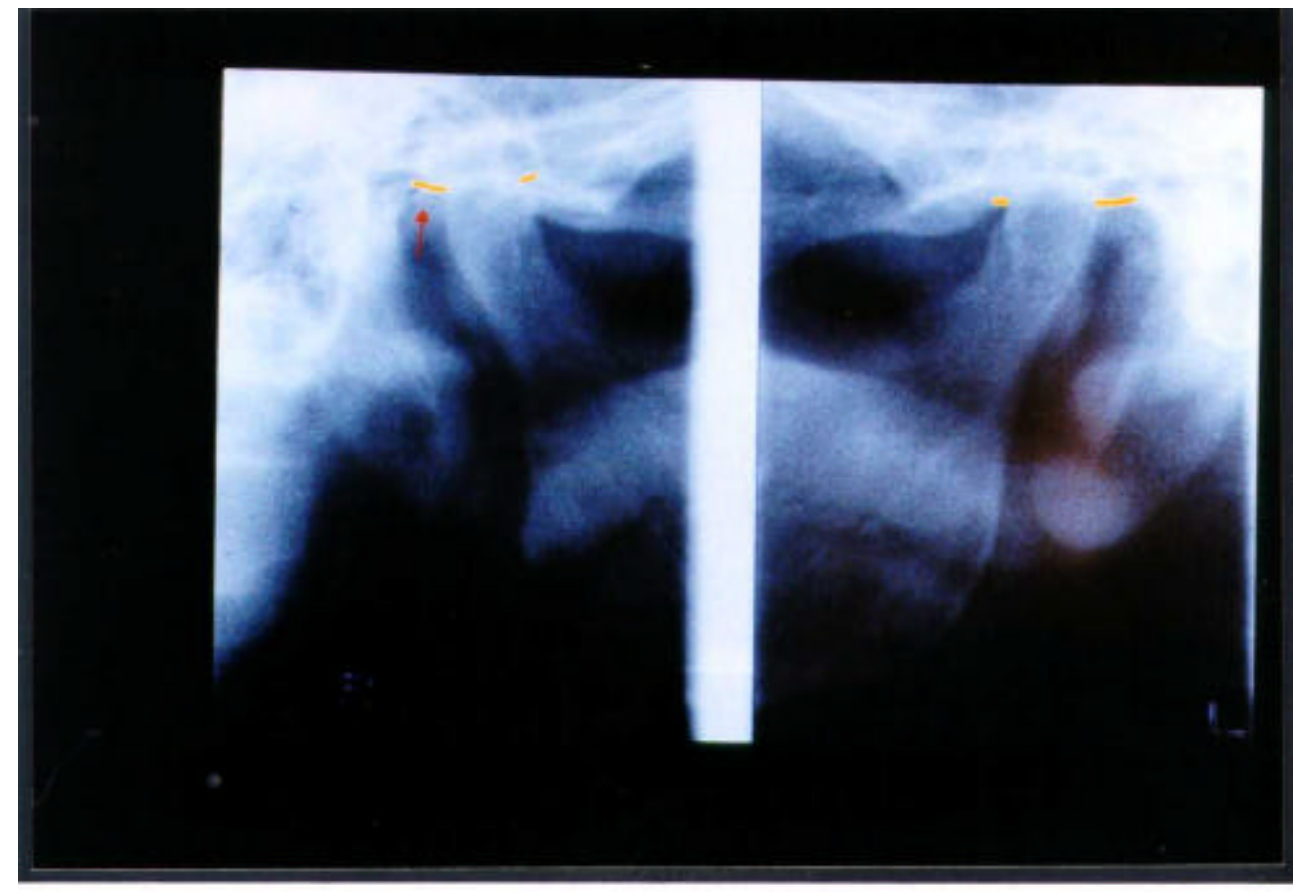

2.1- Radiografia mostrando a posição condilar com a prótese nova. 
6- DISCUSSÃO 


\section{6- DISCUSSÃO}

Atualmente, as radiografias da ATM têm demonstrado papel importante no diagnóstico das DTM's. Devido a vários fatores, existe uma grande dificuldade na obtenção de uma radiografia precisa. $\mathrm{O}$ primeiro deles é a grande quantidade de estruturas anatômicas superpostas. Assim, o eixo central dos raios-x deve evitar a densa porção petrosa do osso temporal, facilitando a visualização dos componentes da ATM. Há ainda, como fatores secundários, a variação do tamanho e forma das estruturas cranianas de cada indivíduo ${ }^{33}$.YALE ${ }^{68}$, avaliando 1700 côndilos, creditou que uma correta avaliação radiográfica da ATM exige procedimentos especializados e um total conhecimento da extensa variação das formas condilares.

No corrente trabalho, houve a presença constante de superposição de imagens e quaisquer dúvidas foram, de imediato, solucionadas junto ao Departamento de Estomatologia da FOB-USP. Contudo, a dificuldade de interpretação sempre representará uma limitação de todo estudo que envolva imagens da ATM.

A falta de padronização de uma técnica radiográfica e dos examinadores também contribui para o insucesso da interpretação de radiografias seriadas. Para minimizar erros de padronização, WEINBERG ${ }^{62}$, em 1973, introduziu um posicionador de suporte para cabeça, obtendo mínimas distorções de imagem.

Da mesma forma, nossa pesquisa, preocupou-se em orientar os pacientes, para que as radiografias fossem registradas de forma padronizada. 
O aparelho de registro das planigrafias possibilitou que os pacientes fossem posicionados de acordo com a linha média e mantivessem a cabeça em posição, através de dois suportes laterais acoplados.

De acordo com outras avaliações, quando se comparou pacientes antes e após o tratamento para DTM's, a variabilidade intra-examinador foi menor do que a interexaminador, sendo isto uma grande vantagem na eliminação de erros de interpretação ${ }^{3,27}$. LIEDBERG; RHOLIN; PERLENNART ${ }^{27}$ observaram que variações intra e interexaminadores, em avaliações da posição condilar, devem sempre ser esperadas, mesmo que sejam obtidas através de procedimentos padronizados. Esta fragilidade na interpretação é considerada uma limitação das técnicas radiográficas ${ }^{27}$. $\mathrm{Na}$ avaliação das planigrafias transferidas ao computador, nós optamos, no presente trabalho, pela análise intraexaminador.

As técnicas radiográficas mais utilizadas para visualização da posição condilar são as tomografias e as TR's. Muito se discute sobre qual dos métodos confere melhor interpretação de resultados ${ }^{12,24,25,43,48,63}$.

Numa conferência dos presidentes da Associação Americana de Odontologia (ADA), em 1982, concluiu-se que existiam insuficientes evidências suportando a excentricidade da posição condilar como um sinal de diagnóstico de DTM's e também questionou-se a validade das TR's freqüentemente utilizadas ${ }^{12}$.

AQUILINO et $a l{ }^{1}$ observaram que TR's não podem confiavelmente determinar a relação anatômica côndilo/fossa, tendo em vista a subjetividade deste método de avaliação. Fontes de variação possibilitando 
erros de interpretação das TR's estão concentradas no eixo de orientação utilizado e variação morfológica da anatomia da ATM.

Entretanto, MUTO et al. ${ }^{36}$, FARRAR ${ }^{10}$, RIEDER; MARTINOFF ${ }^{50}$, WEINBERG ${ }^{59,61}$, MONGINI ${ }^{35}$ afirmaram que as TR's têm um papel significativo no diagnóstico das DTM's.

VAN SICKELS; BIANCO; PIFER ${ }^{57}$ mostraram que as TR's obtidas com angulações maiores do que $20^{\circ}$ tiveram distorções significativas, quando registradas com máxima abertura bucal. Entretanto, afirmaram que as TR's servem, mesmo assim, como um indicador da posição condilar e que, quando houvessem dúvidas decorrentes do diagnóstico radiográfico ou exame clínico, tomografias e artrotomografias deviam ser sugeridas.

PULLINGER; HOLLENDER ${ }^{43}$, em 1985, e MONGINI ${ }^{35}$, em 1981, consideraram que as TR's são efetivas somente quando usadas em conjunção com as tomografias.

Por outro lado, as tomografias possuem um diagnóstico superior às TR's $8,9,12,24,34,45,46,47$, conferindo uma resolução com menor superposição de imagens, além de oferecer uma visualização mais ampla do que as TR's, que só compreendem a porção lateral do côndilo ${ }^{25,66}$.

KNOERNCHILD; AQUILINO; RUPRECHT ${ }^{25}$ realizaram um estudo comparativo entre TR's e tomografias, a partir de cuidadoso controle das angulações das tomadas radiográficas e das dimensões dos espaços articulares, verificando que somente as tomografias refletiram precisamente 
a relação côndilo/fossa. A distorção das imagens das TR's são causadas devido à projeção da superfície articular do lado oposto.

Apesar de resultarem uma imagem turva, as tomografias constituem em um método preciso de avaliação da posição condilar anatômica ${ }^{1,12,25}$, bem como do deslocamento condilar ${ }^{43}$. Em contraposição, as TR's resultam em imagens distorcidas do espaço articular e da concentricidade condilar, o que leva ao questionamento desta técnica para avaliação e diagnóstico das DTM's ${ }^{1,12,25,43}$.

Sendo assim, em nosso estudo, foi empregada a planigrafia como técnica radiográfica para avaliação da posição condilar, que representa a imagem de uma tomografia plana.

A posição condilar em MIH tem sido considerada como importante no diagnóstico das DTM's. A variação desta posição é normalmente percebida pela manhã, sendo continuada por localizações diferentes nos períodos vespertino e noturno. Fatores como estar em repouso ou dormindo e ter se alimentado podem justificar esta variação em aproximadamente $0,4 \mathrm{~mm}^{67}$.

Muitos trabalhos têm associado a não concentricidade condilar com desarranjos internos, artralgias e remodelações desarmônicas dos côndilos 10, 57, 59, 60. PRINGLE ${ }^{42}$, em 1918, baseando-se no mau posicionamento condilar, aventou pela primeira vez a possibilidade desta situação estar relacionada com DTM's. 
Numa avaliação de mais de 320 pacientes, dores agudas relacionadas a deslocamentos condilares foram encontradas numa incidência de $90 \%{ }^{60}$. MIKHAIL; ROSEN ${ }^{33}$, confirmando estes valores, avaliaram que o deslocamento posterior do côndilo ocorreu em 53 a $70 \%$ dos pacientes com DTM's, enquanto que aproximadamente $1 / 3$ dos deslocamentos condilares foi visto no grupo controle (sem desordens).

Em interpretações de TR's, FARRAR ${ }^{10}$ observou que a posição posterior do côndilo estaria associada com o deslocamento anterior do disco articular. WEINBERG ${ }^{59}$, por sua vez, verificou que a posição mais posterior do côndilo se tornava mais freqüente em estágios mais agudos e dolorosos das DTM's.

Em contrapartida, a variação póstero-anterior dos côndilos pode estar presente em indivíduos assintomáticos ${ }^{4,23,64}$.

Em nosso estudo, mostramos também que mesmo em pacientes desdentados totais assintomáticos a posição condilar oscilou, principalmente para anterior, sem quaisquer sinais ou sintomas de desordens musculares e/ou articulares.

A grande maioria dos estudos abordam a posição condilar em pacientes dentados $1,8,22,25,27,34,36,43,44,45,48,57,60,61,62,65,68$. HATJIGIORGIS et al. ${ }^{16}$, RAUSTIA et al. ${ }^{49}$, através de tomografias, observaram que os côndilos em desdentados totais (todos com PT's) estavam posicionados mais para anterior do que em indivíduos dentados. 
Em nosso trabalho, através de planigrafias, comparamos a posição condilar em desdentados totais antes e após instalação de PT's novas e observamos que, na primeira tomada radiográfica, todos os côndilos estavam mais para anterior e que, em $75 \%$ da amostra, a posição condilar apresentou uma tendência para um deslocamento para posterior após a instalação das PT's novas, apesar dos côndilos terem permanecido em uma posição anterior ou concêntrica. Os sensíveis deslocamentos condilares observados após a instalação das PT's novas possivelmente ocorreram devido às variadas manipulações dos profissionais para a posição de trabalho (RC).

Duas das possíveis causas do deslocamento posterior do côndilo, segundo PERRY ${ }^{38}$, são o overbite profundo e a má oclusão classe II de Angle. Em contrapartida a este pensamento, PULLINGER et al. ${ }^{47}$, num estudo da relação da posição condilar com fatores oclusais, numa população assintomática, não mostrou qualquer tipo de correlação, tendo o overbite variado entre 0 a $10 \mathrm{~mm}$.

Os motivos sugeridos como possíveis causas para deslocamentos condilares são os fatores oclusais, como mordidas cruzadas ou perda dos dentes posteriores ${ }^{55}$. Há ainda a possibilidade de assimetria condilar e isto ocorreria provavelmente devido a uma assimetria anatômica natural na relação côndilo/fossa ${ }^{45}$ ou pelo hábito de mastigação unilateral ${ }^{8}$. Na nossa avaliação em desdentados totais, a perda total dos dentes é o principal motivo que justificaria os deslocamentos condilares observados.

A conduta diante de posições descentralizadas condilares tem sido o uso de terapias de reposicionamento, geralmente irreversíveis ${ }^{58,59,60,61,62 .}$ WEINBERG ${ }^{58,62}$ sugeriu os termos relação cêntrica funcional e relação 
cêntrica disfuncional; este último para os côndilos não centralizados na fossa glenóide quando do deslize em RC, do ponto de vista radiográfico. Como tratamento, sugeriu a centralização dos côndilos através de ajustes oclusais por desgaste seletivo e reabilitações protéticas. MONGINI ${ }^{34}$ acrescentou a utilização de placas oclusais e ortodontia, obtendo resultados satisfatórios por meio de acompanhamento tomográfico em intervalos de 9 a 44 meses. A $\mathrm{RC}$ seria funcional quando coincidisse com a MIH e, concomitantemente a isso, os côndilos estivessem concêntricos ou ainda, na presença de um deslize cêntrico, houvesse uma sincronia de sentido deste com o movimento do côndilo na fossa ${ }^{58,62}$.

A única conduta aplicada aos pacientes, desse nosso trabalho, consistiu de substituir as próteses antigas por próteses novas, restabelecendo-se as dimensões verticais e horizontais perdidas, a capacidade mastigatória, a harmonia oclusal e a estética.

MONGINI ${ }^{34}$ creditou, como consequiência do deslocamento condilar e por conseguinte mandibular, uma possível disfunção dos músculos mastigatórios gerando dor por mioespasmos. Acrescentou que o deslocamento condilar pode ser seguido de variação na forma devido à remodelação óssea e que o desequilíbrio desta levará à degeneração articular.

Em nossa pesquisa, a tendência de deslocamento dos côndilos para posterior ou anterior, provavelmente, não trará consequiências danosas ao paciente, tendo em vista que a variação condilar em indivíduos assintomáticos não seja indicativo de sinais e sintomas de DTM's. 
7- CONCLUSÕES 


\section{7- CONCLUSÕES}

De acordo com o exposto, pode-se concluir que:

1- A posição condilar nos desdentados totais está situada mais anterior na fossa glenóide;

2- Houve uma tendência de deslocamento para posterior dos côndilos, com a instalação das próteses totais novas, mesmo que essa posição assumida ainda permaneça levemente para anterior;

3- Não foi possível determinar, através deste estudo, que a posição condilar esteja relacionada com algum sinal ou sintoma de DTM.

4- Não houve qualquer tipo de relação estatisticamente significativa entre aumento da DVO e variação da posição condilar, tendo em vista que a alteração ocorrida ao nível articular pode também ser verificada no sentido superior ou inferior; 


\section{8- REFERÊNCIAS BIBLIOGRÁFICAS}

1- AQUILINO, S.A.; MATTESON, S.R.; HOLLAND, G.A.; PHLLIPS, C. Evaluation of condylar position from temporomandibular joint radiographs. J. Prosth. Dent., v.53, n.1, p.88-97, Jan., 1985.

2- ARTUN, J.; HOLLENDER, L.G.; TRUELOVE, E.L. Relationship between orthodontic treatment, condylar position, and internal deragement in the temporomandibular joint. Am. J. Orthod. Dentofac. Orthop., v.101, n.1, p.48-53, Jan., 1992.

3- BLAIR, G.S.; CHALMERS, I.M.; LEGGAT, T.G.; BUCHANAN, W.W. Circular tomography of the temporomandibular joint. Oral. Surg., v.35, p.416-27, 1973.

4- BLASCHKE, D.D.; BLASCHKE, T.J.; Normal TMJ bony relationships in centric occlusion. J. Dent. Res., v.60, p.98104, 1981.

5- CARLSSON, G.E. Symptoms of mandibular dysfunction in complete denture weares. J. Dent., v.4, n.6, p.265-70, 1976.

6- CARWELL, M.L.; McFALL JR., W.T. Centric relation determinations: Clinical and radiographic comparisons. J. Periodontol. v.52, n.7, p.347-53, July, 1981. 
7- CHOY, E.; SMITH, D.E.. The prevalence of temporomandibular joint disturbances in complete denture patients. J. Oral Rehabil., v.7, p.331-52, 1980.

8- COHLMIA, J.T.; GHOSH, J.; SINHA, P.K.; NANDA, R.S.; CURRIER, G.F. Tomographic assessment of temporomandibular joints in patients with malocclusion. Angle Orthodont., v.66, n.1, p.27-35, 1996.

9- EKDBERG, E.; SABET, M.E.; PETERSSON, A.; NILNER, M. Occlusal appliance theraphy in a short-term pespective in patients with temporomandilbular disorders correlated to condyle position. Int. J. Prosth., v.11, n.3, p.263-8, 1998.

10- FARRAR, W.B. Characteristics of the condylar path in internal derragements of the TMJ. J. Prosth. Dent., v.39, p.319-23, 1978.

11- GRAY, R.J.M.; QUAYLE, A.A.; HORNER, K. The effects of positioning variations in transcranial radiographs of the temporomandibular joint: a laboratory study. Britsh J. of Oral Maxillofac. Surg., v.20, n.4, p.241-9, Aug., 1991.

12- GRIFFITHS, R.M. Report on the president's conference on the examination, diagnosis, and management of temporomandibular disorders. J. Am. Dent. Assoc., v.106, p.75-77, 1983. 
13- GROSS, M. The effect of increasing occlusal vertical dimension on transcranial radiographic projections of the temporomandibular joints. J. Prosth. Dent., v.60, n.4, p.491-9, Oct., 1988.

14- HANSEN, C.A.; AXINN, S. Incidence of mandibular dysfunction symptoms in individuals who remove their complete dentures during sleep. J. Prosth. Dent., v.51, n.1, p.16-8, Jan., 1984.

15- HANSSON, L.G; HANSSON, T.; PETERSSON, A. A comparisom between clinical and radiologic findings in 259 temporomandibular joint patients. J. Prosth. Dent., v. 50, n.1, p.89-94, July, 1983.

16- HATJIGIORGIS, C.G.; GRISIUS, R.J.; FENSTER, R.K.; NEFF, P.A. A tomografic study of tempormandibular joint of edentulous patients. J. Prosth. Dent., v.57, n.3, p.354-8, March, 1987.

17- HEDEGARD, B.; LUNDBERG, M. The temporomandibular joint in patients with immediate upper dentures. Acta Odont. Scand., v.23, p. 163-73, 1965.

18- HELlSING, G.; ISBERG-HOLM, A.; McWILLIAM, J. A comparative study of two techniques for recording centric relation. Dentomaxillofac. Radiol., v.12, n.1, p.5-12, 1983. 
19- HESSE, K.L.; ARTUN, J.; JOONDEPH, D.R.; KENNEDY, D.B. Changes in condylar position and occlusion associated with maxillary expansion for correction of functional unilateral posterior crossbite. J. Orthod. Dentofac. Orthop., v.111, n.4, p.410-8, April, 1997.

20- HONGCHEN, L.; JILIN, Z.; NING, L. Edentulous position of temporomandibular joint. J. Prosth. Dent., v. 67, n.3, p.401-4, March, 1992.

21- ISMAIL, Y.H.; ROKNI, A. Radiographic study of condylar position in centric relation and centric occlusion. J. Prosth. Dent.,v 43,n.3, p.328-30, March, 1980.

22- KAPA, S.F.; TYNDALL, D.A.; ZULLO, T.G.; BAGNELL, C.R.; HILL, C. Assessing condylar changes with digital subtraction radigraphy. Oral Surg. Oral Med. Oral Pathol., v.75, n.2, p.247-52, Feb., 1993.

23- KATZBERG, R.W.; KEITH, D.A.; TEM EICK, W.R.; GURALNICK, W.C. Internal derangements of the temporomandibular joint: an assessment of condylar position in centric occlusion. J. Prosth. Dent., v.49, n.2, p.250-4, Feb., 1983.

24- KLEIN, I.E.; BLATTERFEIN, L.; MIGLINO, J.C. Comparison of the fidelity of radiographs of mandibular condyles made by 
different techniques. J. Prosth. Dent., v.24, n.4, p.419-52, Oct., 1970.

25- KNOERNCHILD, K.L.; AQUILINO, S.A.; RUPRECHT, A. Transcranial radiography and linear tomography: A comparative study. J. Prosth. Dent., v.66, n.2, p.239-50, Aug., 1991.

26- KUNDERT, M. Limits of perceptibility of condyle displacements on temporomandibular joint radiographs. J. Oral Rehabil., v.6, n.4, p.375-83, Oct., 1979.

27- LIEDBERG, J.; ROHLIN, M.; PER-LENNART, W. Observer perfomance in assessment of condylar position in temporomandibular joint radiograms. Acta Odont. Scand., v.43, n.1, p.53-8, March, 1985.

28- LINDBLOM, G. Technique for roentgen-photographic registration of the different condyle positions in the temporomandibular joint. Dental Cosmos., v.78, n.12, p.1227-35, Dec., 1936.

29- LOGSDON, L.C.; CHACONAS, S.J. Laminographic evaluation of the temporomandibular joint. (abstract 556). J. Dent Res., v.54, p.184, 1975. 
30- LOISELLE, R.J. Relation of occlusion to temporomandibular joint dysfunction: the prosthodontic viewpoint. J. Am. Dent. Assoc., v.79, p.145-6, July, 1969.

31- MARTIN, T.B. An investigation of the position of the mandibular condyle and its interpretation from temporomandibular joint radiographs. Am. J. Orthod., v.37, n.8, p.277-8, May, 1951.

32- MEJERSJO, C.; HOLLENDER, L. TMJ pain and dysfunction: relation between clinical and radiographics findings in the short and long-term. Scand. J. Dent. Res., v.92, p.241-8, 1984.

33- MIKHAIL, M.G.; ROSEN, H. The validity of temporomandibular joint radiographs using the head positioner. J. Prosth. Dent., v.42, n.4, p.441-6, Oct., 1979.

34- MONGINI, F. Condylar remodeling after occlusal therapy. J. Prosth. Dent., v. 43, n.5, p.568-77, May, 1980.

35- MONGINI, F. The importance of radiography in the diagnosis of TMJ dysfunctions. J. Prosth. Dent., v.45, n.2, p.186-98, Feb., 1981.

36- MUTO, T.; KOHARA, M.; KANAZAWA, M.; KAWAKAMIS, $\mathrm{J}$. The position of the mandibular condyle at maximal mouth 
opening in normal subjects. J. Oral Maxillofac. Surg. v.52, n.12, p.1269-72, Dec., 1994.

37- NILNER, M.; PETERSSON, A. Clinical and radiological findings related to treatment outcome in patients with temporomandibular disorders. Dentomaxillofac. Radiol., v.24, n.2, p. 128-31, 1995.

38- PERRY, H.T. Relation of occlusion to temporomandibular dysfunction: the orthodontic viewpoint. J. Am. Dent. Assoc., v. 79, p.269, 1969.

39- PIRTTINIEMI, P.; RAUSTIA, A.; KANTOMAA, T.; PYHTINEN, J. Relationships of bicondylar position to occlusal asymmetry. Eur. J. Orthod., v.13, p.441-5, 1991.

40- PRETI, G.; FAVA., C. Lateral transcranial radiography of temporomandibular joints. Part I: Validity in skulls and patients. J. Prosth. Dent., v. 59, n.1, p.85-93, Jan., 1988.

41- PRETI, G.; SCOTTI, R.; TURBILGLIO, G.; SCALA, C. Anatomic study of condylar position at maximum intercuspation. J. Prosth. Dent., v.47, n.4, p.445-7, April, 1982.

42- PRINGLE, J.H. Displacement of the mandibular meniscus and its treatment. Br. J. Surg., v.6, p.385-9, 1918. 
43- PULLINGER, A.; HOLLENDER, L. Assessmennt of mandibular condyle position: A comparison of transcranial radiographs and linear tomograms. Oral Surg. Oral Med. Oral Pathol., v.60, n.3, p.329-34, Sep., 1985.

44- PULLINGER, A.; HOLLENDER, L. Variation in condyle-fossa relationships according to different methods of evaluation in tomograms. Oral Surg. Oral Med. Oral Pathol., v.62, p.719-27, 1986.

45- PULliNGER, A.G.; HOLLENDER, L.; SOLBERG, W.K.; PETERSSON, A. A tomographic study of mandibular condyle position in a asymptomatic population. J. Prosth. Dent., v.53, n.5, p.706-13, May, 1985.

46- PULliNGER, A.G.; SOLBERG, W.K.; HOLLENDER, L.; GUICHET, D. Tomographic analysis of mandibular condyle position in diagnostic subgroups of temporomandibular disorders. J. Prosth. Dent., v.55, n.6, p.723-9, June, 1986.

47- PULLINGER, A.G.; SOLKBERG, W.K.; HOLLENDER, L.; PETERSSON, A. Relationship of mandibular condylar position to dental occlusion factors in a asymptomatic population. Am. J. Orthod. Dentofac., v.91, n.3, p.200-6, March, 1987.

48- PULLINGER, A.G.; WHITE, S.C. Efficacy of TMJ radiographs in terms of expected versus actual findings. Oral Surg. 
Oral Med. Oral Pathol. Oral Radiol. Endod., v.79, n.3, p.367-74, March, 1995.

49- RAUSTIA, A.M.; PIRTTINIEMI, P.; SALONEN, M.A.M.; PYHTINEN, J. Effect of edentulousness on mandibular size and condyle-fossa position. J. Oral Rehabil., v.25, n.3, p.174-9, March, 1998.

50- RIEDER, C.E.; MARTINOFF, J.T. Comparison of the multiphasic dysfunction profile with lateral transcranial radiographs. J. Prosth. Dent. v.52, n.4, p.572-80, Oct., 1984.

51- SAKUDA, M.; TANNE, K.; TANAKA, E.; TAKASUGI, H. An analytic method for evaluating condylar position in the TMJ and its application to orthodontic patients with painful clicking. Am. J. Orthod. Dentofac. Orthop., v.101, n1, p.88-96, Jan., 1992.

52- SAKURAI, K.; SAN GIACOMO, T.; ARBREE, N.S.; YURKSTAS, A.A. A survey of temporomandibular joint dysfunction in completely edentulous patients., J. Prosth. Dent., v. 59, n.1, p.81-5, Jan., 1988.

53- SHAFAGH, I.; YADER, J.L.; THAYER, K.E. Diurnal variance of centric relation position. J. Prosth. Dent., v.34, n.5, p.57482, Nov., 1975. 
54- SMITH, N.J.D.; HARRIS, M. Radiology of the temporomandibular joint and condylar head. Br. Dent. J., v.129, n.20, p.361-8, Oct., 1970.

55- THOMPSON JR. Abnormal function of the temporomandibular joints and related musculature. Angle Orthod. v.24, p.51241, 1970.

56- TUCKER, T.N. Head position for transcranial temporomandibular joint radiographs. J. Prosth. Dent., v.52, n.3, p.426-31, Sep., 1984

57- VAN SICKELS, J.E.; BIANCO JR., H.J.; PIFER, R.G. Transcranial radiographs in the evaluation of craniomandibular disorders. J. Prosth. Dent., v.49, n.2, p.244-9, Feb., 1983.

58- WEINBERG, L.A. Optimum temporomandibular joint condyle position in clinical practice. Int. J. Period. Rest. Dent., v.1, p.11-27, 1985.

59- WEINBERG, L.A. Posterior bilateral condylar displacement: its diagnosis and treatment. J. Prosth. Dent., v. 36, p.426, 1976

60- WEINBERG, L.A. Role of condylar position in TMJ dysfunctionpain syndrome. J. Prosth. Dent., v. 41, n.6, p.636-43, June, 1979. 
61- WEINBERG, L.A. Superior condylar displacement: its diagnosis and treatment. J. Prosth. Dent., v.34, p.59, 1975

62- WEINBERG, L.A. Temporomandibular joint function and its effect on centric relation. J. Prosth. Dent., v.30, n.2, p.17695, Aug., 1973.

63- WILKIE, N.D.; HURST, T.L.; MITCHELL, D.L. Radiographic comparisons of condyle-fossa relationships during maxillomandibular registration made by different methods . J. Prosth. Dent., v.32,n.5, p.529-33, Nov., 1974.

64- WILLIAMS, B.H. Oriented lateral temporomandibular joint laminographs. Angle Orthod., v.53, n.3, p.228-33, July, 1983.

65- WILLIAMS, B.H. Tomographic stability of condyle fossa relationships in 40 treated tempormandibular disorders patients. J. Prosth. Dent., v.79, n.5, p.570-4, May, 1998.

66- WILLIAMSON, E.H. Laminographic study of mandibular condyle position when recording centric relation. J. Prosth. Dent., v. 39, n.5, p.561-4, May, 1978.

67- WISKOTT, H.W.A.; BELSER, U.C. A rationale for a simplified occlusal design in restorative dentistry: historical review 
and clinical guidelines. J. Prosth. Dent., v.73, n.2, p.16982, Feb., 1995

68- YALE, R. Radiographic evaluation of the temporomandibular joint. J. Am. Dent. Assoc., v.79, p.102, 1979. 


\section{8- ABSTRACT}

Condyle position have been questioned as a relevant factor in detection of signs and symptoms of TMD. For a long time, it was determined that condylar concentricity would reflect an ideal position for the pacient. However, others studies demonstrated that it was possible to visualize that condyles were not always concentic in assintomatic pacient. This study evaluated the condylar position before and after instalation of new complete dentures using plain tomography of TMJ's. Twelve completely edentulous patients were selected randomly to have new complete dentures. A questionare was filled out and plain tomograms were taken with old and new complete dentures inserted. Only one examiner evaluated the questionare and tomograms using Corel Draw 8 image software. According to the metodology and statical analysis, it was noted that condyle position in completely edentulous patients in the first tomogram was anterior in $100 \%$ of patients. After insertion of new dentures, the condyles had a tedency to be posteriorly positioned relative to the initial tomogram in $75 \%$ of the, $16,7 \%$ of the condyles deslocated anteriorly, and in $8,3 \%$ did not change position. Of the 18 condyles (75\% of total) with posterior displacement, only one condyle assumed a true, although slight, posterior position, with the others located in a concentric or anterior position. There was no any statical correlation between variation of condylar position and vertical dimension of occlusion. Probably, the condylar displacement occurred due to variations in the manipulation technique applied by the professionals for centric relation registration. Base on the literature, the tendency to posterior location of condyles of completely edentulous patients after new complete dentures insertion will not cause any damage in assintomatic patients. 